\title{
Towards a structural understanding of allosteric drugs at the human calcium-sensing receptor
}

Katie Leach ${ }^{1}$, Karen J Gregory ${ }^{1}$, Irina Kufareva ${ }^{2}$, Elham Khajehali ${ }^{1}$, Anna E Cook ${ }^{1}$, Ruben Abagyan ${ }^{2}$, Arthur D Conigrave ${ }^{3}$, Patrick M Sexton ${ }^{1}$, Arthur Christopoulos ${ }^{1}$

${ }^{I}$ Drug Discovery Biology, Department of Pharmacology, Monash Institute of Pharmaceutical Sciences, Monash University, 381 Royal Parade, Parkville, VIC 3052, Australia; ${ }^{2}$ Skaggs School of Pharmacy and Pharmaceutical Sciences, University of California, San Diego, 9500 Gilman Drive, La Jolla, CA 92037, USA; ${ }^{3}$ School of Molecular Bioscience, Charles Perkins Centre, University of Sydney, NSW 2006, Australia

Drugs that allosterically target the human calcium-sensing receptor (CaSR) have substantial therapeutic potential, but are currently limited. Given the absence of high-resolution structures of the CaSR, we combined mutagenesis with a novel analytical approach and molecular modeling to develop an "enriched" picture of structure-function requirements for interaction between $\mathrm{Ca}^{2+}{ }_{0}$ and allosteric modulators within the CaSR's 7 transmembrane (7TM) domain. An extended cavity that accommodates multiple binding sites for structurally diverse ligands was identified. Phenylalkylamines bind to a site that overlaps with a putative $\mathrm{Ca}^{2+}{ }_{0}$-binding site and extends towards an extracellular vestibule. In contrast, the structurally and pharmacologically distinct AC-265347 binds deeper within the 7TM domains. Furthermore, distinct amino acid networks were found to mediate cooperativity by different modulators. These findings may facilitate the rational design of allosteric modulators with distinct and potentially pathway-biased pharmacological effects.

Keywords: allosteric modulation; drug discovery; G protein-coupled receptor; molecular modeling; mutagenesis; structural biology

Cell Research (2016) 26:574-592. doi:10.1038/cr.2016.36; published online 22 March 2016

\section{Introduction}

The human calcium-sensing receptor (CaSR) is a class C G protein-coupled receptor (GPCR), characterized by a large extracellular N-terminal venus fly trap (VFT) domain connected to 7 transmembrane (TM) spanning domains by a cysteine-rich linker. It primarily operates as a "calciostat" to control extracellular calcium $\left(\mathrm{Ca}^{2+}{ }_{0}\right)$ concentrations in the body principally via its expression in the parathyroid gland, where it negatively regulates parathyroid hormone (PTH) release (reviewed in [1]), and in the renal cortical thick ascending limb, where it negatively regulates renal $\mathrm{Ca}^{2+}{ }_{0}$ reabsorption $[2,3]$. In addition, elevated $\mathrm{Ca}^{2+}{ }_{0}$ stimulates CaSR-mediated cal-

Correspondence: Katie Leach ${ }^{\mathrm{a}}$, Arthur Christopoulos ${ }^{\mathrm{b}}$

${ }^{a}$ E-mail: katie.leach@monash.edu

${ }^{\mathrm{b}}$ E-mail: arthur.christopoulos@monash.edu

Received 20 July 2015; revised 18 December 2015; accepted 28 January 2016; published online 22 March 2016 citonin secretion from thyroid C cells [4], and decreases bone resorption via CaSRs expressed on osteoblasts and osteoclasts (reviewed in [5]).

Due to its control of PTH secretion and consequent effects such as changes in bone turnover, the CaSR has marked therapeutic potential for the treatment of disorders such as hyper- and hypoparathyroidism, and osteoporosis. This has led to the development of drugs that increase or attenuate CaSR activity. The phenylalkylamine, cinacalcet (Mimpara/Sensipar), a type II "calcimimetic" that enhances CaSR activity by acting as a positive allosteric modulator (PAM), was the first allosteric GPCR drug on the market, and is approved for the treatment of some instances of hyperparathyroidism; since that time, the study of allosteric GPCR modulators has become an area of intense research [6]. Calcilytics, which reduce CaSR activity by behaving as negative allosteric modulators (NAMs), have been trialed as treatments for osteoporosis due to their ability to stimulate PTH release, which has beneficial effects on bone mass and density 
when elevated transiently [7].

Although effective in treating hyperparathyroidism, cinacalcet use is limited due to its propensity to induce hypocalcaemia [8]. Furthermore, osteoporotic patients treated with calcilytics have failed to show improvements in bone mass and density in clinical trials [9-11]. Thus, there is an unmet need to develop novel PAMs and NAMs that show enhanced clinical efficacy with reduced adverse effects. Encouragingly, new classes of CaSR modulators have now been disclosed, and more than 10 structurally distinct scaffolds confer PAM or NAM activity $[12,13]$. Moreover, some of these modulators display unique pharmacology compared to the prototypical modulators. For instance, AC-265347 and calcimimetic $\mathrm{B}$, which are structurally distinct from the prototypical phenylalkylamine PAMs, have a reduced propensity to cause hypocalcemia in rats $[14,15]$. Interestingly, both AC-265347 and calcimimetic B also differ from phenylalkylamine PAMs in their ability to preferentially modulate some downstream signaling events arising from the CaSR to the relative exclusion of others, a phenomenon referred to as "biased allosteric modulation" [16-20]. This may underlie observed differences in the in vivo pharmacological profiles of AC-265347 and calcimimetic B $[16,21]$, which could offer improved therapeutic benefits.

Despite this promise, a better understanding of how the allosteric activity of CaSR modulators is mediated is still required to aid in the rational design of improved CaSR therapeutics. To date, however, there is limited understanding of the structural basis for CaSR PAM and NAM activity. This is in part because no high-resolution structure has been solved for the CaSR, and the binding sites for these modulators have thus not been fully elucidated. Moreover, most mutagenesis studies, and all molecular modeling studies, performed on the CaSR to date have not differentiated between the contribution of amino acid residues to the affinity of allosteric modulators, which provides information about the binding pocket, versus their contribution to PAM- or NAM-induced modulation of $\mathrm{Ca}^{2+}{ }_{0}$-mediated signaling (i.e., the cooperativity between the modulators and $\mathrm{Ca}^{2+}{ }_{0}$ ), which provides information about the transmission of the allosteric effect. Separation of these molecular properties is critical for elucidating drug-receptor interactions based on structure-function analyses of allosteric drug activity.

Although the exact location of different allosteric binding sites on the CaSR remains somewhat equivocal, evidence suggests that synthetic small-molecule CaSR PAMs and NAMs bind within the 7TM domains, at a location distinct from the primary orthosteric $\mathrm{Ca}^{2+}{ }_{0}{ }_{0}$-binding sites located in the VFT domain. This is supported by the preservation of PAM and NAM activity at a CaSR that lacks the VFT and cysteine-rich domains [22-25], by molecular modeling and mutagenesis studies showing that 7TM domain residues are essential for the activity of prototypical allosteric modulators [26-29], and by the recent solution of crystal structures of the 7TM regions of the related class $\mathrm{C}$ metabotropic glutamate 1 and 5 $\left(\mathrm{mGlu}_{1}\right.$ and $\left.\mathrm{mGlu}_{5}\right)$ receptors that also contain allosteric binding sites for small molecules [30, 31]. However, all high-resolution structural studies to date have involved substantial receptor engineering and/or truncations, and there remains a relative paucity of molecular-level understanding of how different residues in the intact (full length) CaSR contribute differentially to allosteric modulator binding, allosteric modulation of $\mathrm{Ca}^{2+}{ }_{0}$ signaling and the potential for this signaling to be biased between pathways. The current study thus aimed to address these latter issues using an "enriched" structure-function approach that couples mutagenesis focused on the TM regions of the CaSR with analytical pharmacological delineation of mutational effects on affinity and cooperativity, together with molecular modeling (Figure 1A). This achieved new insights into the binding site location, allosteric mode of action and potential for biased signaling of different classes of CaSR modulators.

\section{Results}

Residues that contributed to CaSR expression and signaling

The structures of the CaSR PAMs and NAMs used in this study are shown in Figure 1B and the amino acid substitutions are shown in Figure 1C. The effects of amino acid substitutions on CaSR cell surface expression were first determined (Supplementary information, Table $\mathrm{S} 1$ ). With the exception of $\mathrm{V} 689^{3.41} \mathrm{~A}$ (Ballesteros-Weinstein [32] numbering shown in superscript throughout this manuscript is based on that assigned in [30]), all mutant receptors were expressed at the cell surface at various levels in the range of $\sim 10 \%$ (e.g., I669 $9^{2.57} \mathrm{~A}$ ) to $170 \%$ (e.g., Y $825^{6.57} \mathrm{~A}$ ) of wild-type (WT) CaSR expression. This indicates that residues throughout the 7TM domains are important for folding, stability and trafficking of the CaSR. The effects of mutations on $\mathrm{Ca}^{2+}{ }_{0}$-mediated receptor signaling were subsequently evaluated using $\mathrm{Ca}^{2+}{ }_{\mathrm{i}}$ mobilization assays. TM residues that altered the potency of $\mathrm{Ca}^{2+}{ }_{0}$ were located in all 7TM domains (Supplementary information, Table S1).

Enriched structure-function analysis identifies residues important for PAM and NAM affinity

Next, we investigated the effects of amino acid substi- 

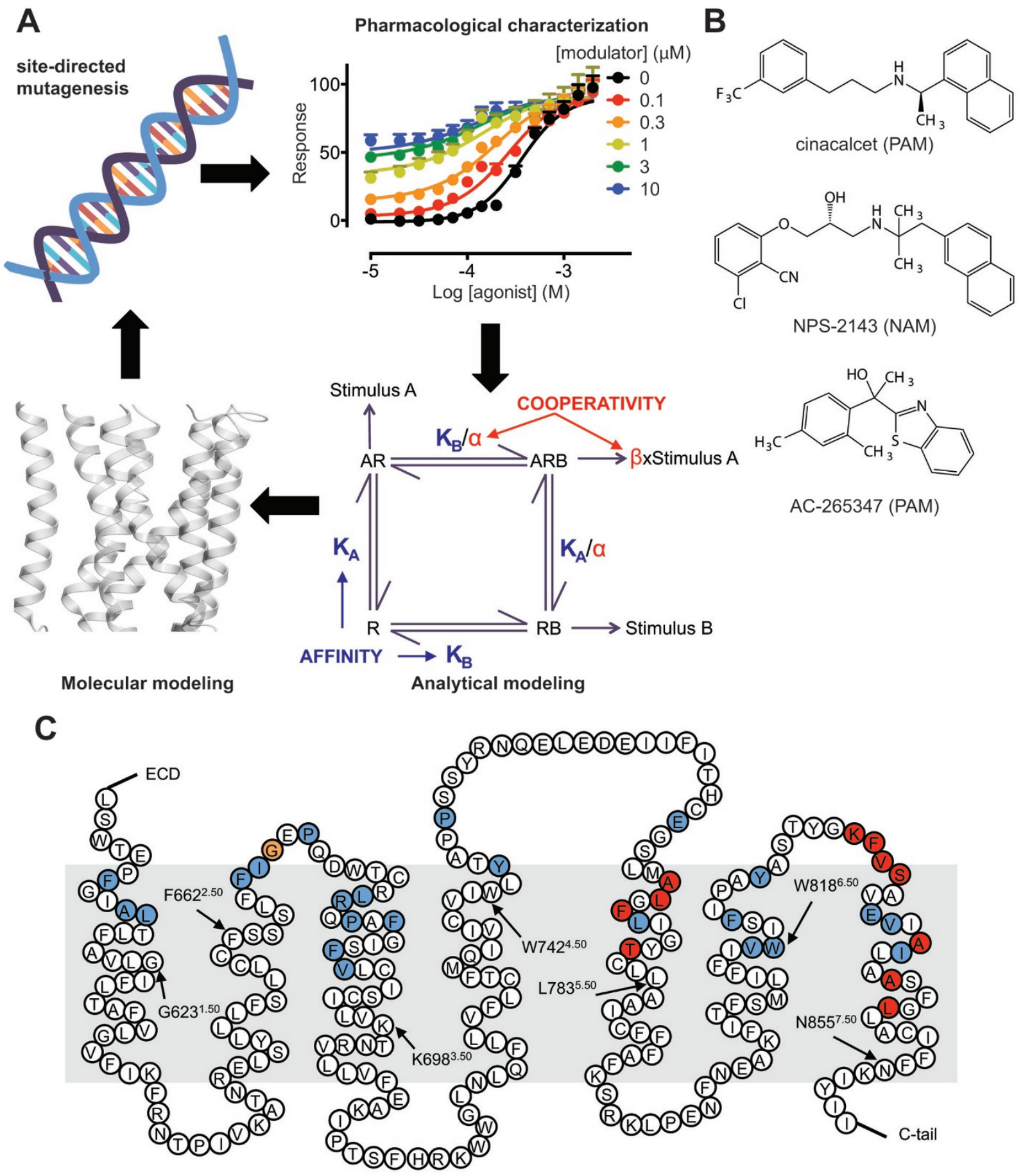

Figure 1 A strategy for enriching allosteric modulator structure-function studies. (A) Mutagenesis was coupled with allosteric analytical modeling to determine amino acid residues that contributed to PAM and NAM binding and allosteric modulation. Mapping important residues onto molecular models of the CaSR's 7TM domains enabled prediction of additional residues to mutate. (B) Structures of PAMs (cinacalcet and AC-265347) and the NAM (NPS-2143) investigated in the current study. (C) Snake diagram of the primary CaSR 7TM domain sequence, indicating residues that were mutated in the current study. Mutations at residues predicted to be important for the binding of the modulators from earlier CaSR molecular models [23-26, 29] are shown in blue. Mutations at homologous CaSR residues that line the $\mathrm{mGlu}_{1}$ or $\mathrm{mGlu}_{5}$ allosteric binding site are shown in red. All engineered mutations were substituted with Ala, with the exception of $A 615^{1.42}, A 772^{5.39}, A 844^{7.39}$ and $A 840^{7.35}$, which were substituted to Val and E837.32 that was also mutated to Asp and lle. The residue highlighted in orange indicates where a naturally occurring mutation alters the activity of some PAMs [18]. Thick black arrows point to the X.50 conserved class C amino acid residues based on the modified Ballesteros-Weinstein numbering system suggested in [30]. 
Table 1 Functional affinity $\left(\mathrm{pK}_{\mathrm{B}}\right)$ and cooperativity $(\log \alpha \beta)$ parameters for CaSR modulators determined in $\mathrm{Ca}^{2+}{ }_{\mathrm{i}}$ mobilization assays as described in Materials and Methods. Data are mean \pm SEM from the indicated number of independent experiments $(n)$.

\begin{tabular}{|c|c|c|c|c|c|c|c|c|c|}
\hline & \multicolumn{2}{|c|}{ Cinacalcet } & \multicolumn{4}{|c|}{ NPS-2143 } & \multicolumn{3}{|c|}{ AC-265347 } \\
\hline & $\mathrm{pK}_{\mathrm{B}}$ & $\log \alpha \beta(\alpha \beta)$ & $n$ & $\mathrm{pK}_{\mathrm{B}}$ & $\log \alpha \beta(\alpha \beta)$ & $n$ & $\mathrm{pK}_{\mathrm{B}}$ & $\log \alpha \beta(\alpha \beta)$ & $n$ \\
\hline WT & $6.34 \pm 0.05$ & $0.43 \pm 0.03(2.7)$ & 29 & $6.66 \pm 0.04$ & $-0.33 \pm 0.05(0.47)$ & 11 & $6.27 \pm 0.08$ & $0.43 \pm 0.09(2.7)$ & 8 \\
\hline $\mathrm{A} 615^{1.42} \mathrm{~V}$ & $6.05 \pm 0.08$ & $0.72 \pm 0.08 *(5.2)$ & 4 & $6.74 \pm 0.05$ & $-0.57 \pm 0.05(0.27)$ & 4 & $7.12 \pm 0.07^{*}$ & $-0.19 \pm 0.09 *(0.65)$ & 4 \\
\hline $\mathrm{L} 616^{1.43} \mathrm{~A}$ & $6.21 \pm 0.09$ & $0.45 \pm 0.10(2.8)$ & 3 & $6.63 \pm 0.13$ & $-0.31 \pm 0.06(0.49)$ & 4 & $6.09 \pm 0.09$ & $0.35 \pm 0.10(2.3)$ & 5 \\
\hline $\mathrm{G} 670^{\mathrm{ECL} 1} \mathrm{~A}$ & $6.47 \pm 0.10$ & $0.25 \pm 0.07(1.8)$ & 4 & $7.38 \pm 0.04 *$ & $-0.53 \pm 0.05(0.30)$ & 5 & $6.16 \pm 0.08$ & $0.48 \pm 0.09(3.0)$ & 4 \\
\hline $\mathrm{P} 672^{\mathrm{ECL} 1} \mathrm{~A}$ & $6.23 \pm 0.15$ & $0.57 \pm 0.11(3.7)$ & 4 & $7.11 \pm 0.14^{*}$ & $-0.54 \pm 0.11(0.29)$ & 4 & $\mathrm{NP}$ & NP & 0 \\
\hline $\mathrm{L} 679^{3.31} \mathrm{~A}$ & $6.09 \pm 0.08$ & $0.55 \pm 0.06(3.5)$ & 5 & $6.87 \pm 0.12$ & $-0.48 \pm 0.11(0.33)$ & 4 & NP & NP & 0 \\
\hline $\mathrm{R} 680^{3.32} \mathrm{~A}$ & $6.11 \pm 0.17$ & $0.56 \pm 0.11(3.6)$ & 4 & $5.93 \pm 0.15^{*}$ & $-0.39 \pm 0.08(0.41)$ & 4 & $6.16 \pm 0.09$ & $0.48 \pm 0.09(3.0)$ & 4 \\
\hline $\mathrm{V} 689^{3.41} \mathrm{~A}$ & NR & NR & 3 & NR & NR & 3 & NR & NR & 3 \\
\hline $\mathrm{Y} 744^{4.52} \mathrm{~A}$ & $6.48 \pm 0.10$ & $0.60 \pm 0.05(4.0)$ & 4 & $6.57 \pm 0.07$ & $-0.10 \pm 0.08(0.79)$ & 4 & $6.13 \pm 0.09$ & $0.53 \pm 0.08(3.4)$ & 4 \\
\hline $\mathrm{P} 748^{\mathrm{ECL} 2} \mathrm{~A}$ & $6.46 \pm 0.06$ & $0.51 \pm 0.06(3.2)$ & 4 & $6.86 \pm 0.05$ & $-0.58 \pm 0.05(0.26)$ & 4 & NP & NP & 0 \\
\hline $\mathrm{E} 767^{\mathrm{ECL} 2} \mathrm{~A}$ & $6.86 \pm 0.20 *$ & $-0.17 \pm 0.15 *(0.68)$ & 3 & $6.62 \pm 0.08$ & $-0.64 \pm 0.08(0.23)$ & 4 & $7.21 \pm 0.07^{*}$ & $-0.09 \pm 0.11 *(0.81)$ & 4 \\
\hline $\mathrm{A} 772^{5.39} \mathrm{~V}$ & $6.79 \pm 0.16^{*}$ & $0.47 \pm 0.05(3.0)$ & 4 & $6.92 \pm 0.08$ & $-0.31 \pm 0.07(0.49)$ & 4 & $6.49 \pm 0.12$ & $0.74 \pm 0.14(5.5)$ & 4 \\
\hline 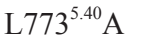 & $6.46 \pm 0.10$ & $0.30 \pm 0.08(2.0)$ & 4 & $6.56 \pm 0.07$ & $-0.63 \pm 0.08(0.23)$ & 4 & $6.28 \pm 0.09$ & $0.64 \pm 0.12(4.4)$ & 4 \\
\hline $\mathrm{F} 775^{5.42} \mathrm{~A}$ & $6.46 \pm 0.12$ & $0.45 \pm 0.09(2.8)$ & 4 & $6.79 \pm 0.08$ & $-0.38 \pm 0.07(0.42)$ & 4 & $6.63 \pm 0.07 *$ & $0.31 \pm 0.07(2.0)$ & 7 \\
\hline $\mathrm{L} 776^{5.43} \mathrm{~A}$ & $6.28 \pm 0.14$ & $0.49 \pm 0.09$ & 4 & $6.21 \pm 0.09^{*}$ & $-0.67 \pm 0.09 *(0.21)$ & 4 & $6.66 \pm 0.08^{*}$ & $0.44 \pm 0.11(2.8)$ & 6 \\
\hline $\mathrm{T} 780^{5.47} \mathrm{~A}$ & $6.03 \pm 0.22$ & $0.20 \pm 0.07(1.6)$ & 4 & $6.31 \pm 0.07$ & $-0.25 \pm 0.05(0.56)$ & 4 & $6.23 \pm 0.09$ & $0.81 \pm 0.12(6.5)$ & 4 \\
\hline $\mathrm{V} 833^{\mathrm{ECL3}} \mathrm{A}$ & $6.94 \pm 0.08^{*}$ & $0.21 \pm 0.06(1.6)$ & 6 & $7.21 \pm 0.07 *$ & $-0.41 \pm 0.06(0.39)$ & 5 & $6.24 \pm 0.08$ & $0.48 \pm 0.10(3.0)$ & 5 \\
\hline $\mathrm{S} 834^{\mathrm{ECL} 3} \mathrm{~A}$ & $6.01 \pm 0.11$ & $0.57 \pm 0.07(3.7)$ & 4 & $7.14 \pm 0.07 *$ & $-0.50 \pm 0.08(0.32)$ & 4 & $6.30 \pm 0.10$ & $0.50 \pm 0.10(3.2)$ & 4 \\
\hline $\mathrm{E} 837^{7.32} \mathrm{~A}$ & NA & NA & 4 & NA & NA & 5 & NA & NA & 4 \\
\hline $\mathrm{E} 837^{7.32} \mathrm{D}$ & $7.11 \pm 0.13^{*}$ & $0.28 \pm 0.12(1.9)$ & 3 & NA & NA & 9 & $6.74 \pm 0.17^{*}$ & $0.67 \pm 0.21(4.7)$ & 4 \\
\hline $\mathrm{E} 837^{7.32} \mathrm{I}$ & NA & NA & 7 & NA & NA & 4 & NA & NA & 5 \\
\hline $\mathrm{V} 838^{7.33} \mathrm{~A}$ & $6.10 \pm 0.07$ & $0.56 \pm 0.06(3.6)$ & 6 & $6.17 \pm 0.17^{*}$ & $-0.27 \pm 0.10(0.54)$ & 5 & $5.85 \pm 0.08$ & $0.83 \pm 0.08(6.8)$ & 4 \\
\hline $\mathrm{A} 840^{7.35} \mathrm{~V}$ & $5.88 \pm 0.11^{*}$ & $0.56 \pm 0.12(3.6)$ & 6 & $6.48 \pm 0.18$ & $-0.29 \pm 0.06(0.51)$ & 5 & $6.74 \pm 0.10^{*}$ & $0.27 \pm 0.11(1.9)$ & 6 \\
\hline $\mathrm{I} 841^{7.36} \mathrm{~A}$ & NA & NA & 5 & NA & NA & 4 & $6.04 \pm 0.10$ & $0.33 \pm 0.10(2.1)$ & 4 \\
\hline $\mathrm{A} 844^{7.39} \mathrm{~V}$ & $6.65 \pm 0.09$ & $0.08 \pm 0.07 *(1.2)$ & 5 & $7.35 \pm 0.05^{*}$ & $-0.27 \pm 0.06(0.54)$ & 6 & $7.27 \pm 0.06^{*}$ & $-0.01 \pm 0.07 *(0.98)$ & 6 \\
\hline $\mathrm{L} 848^{7.43} \mathrm{~A}$ & $6.22 \pm 0.13$ & $0.12 \pm 0.06 *(1.3)$ & 4 & $7.06 \pm 0.05$ & $-0.39 \pm 0.07(0.41)$ & 4 & $6.62 \pm 0.08$ & $0.33 \pm 0.09(2.2)$ & 4 \\
\hline
\end{tabular}

*Denotes significantly different from WT $(P<0.05$, one-way ANOVA with Dunnett's multiple comparisons post test).

NA denotes no or weak modulator activity.

NR denotes no response to $\mathrm{Ca}^{2+}{ }_{0}$.

NP denotes not performed. 
tutions on the functional activities of PAMs and NAMs to identify residues essential for modulator binding. Because no commercial radioligands are available for the CaSR, we tested CaSR-mediated $\mathrm{Ca}^{2+}{ }_{\mathrm{i}}$ mobilization to determine the effects of the mutations $[18,20]$, and analyzed the resulting data with an operational model of allosterism [17] that we have developed to explicitly determine the modulators' functional affinity (referred to herein as $\mathrm{pK}_{\mathrm{B}}$ ) and their overall cooperativity with $\mathrm{Ca}^{2+}{ }_{0}$ $(\alpha \beta)$, at the WT and mutant receptors, as separate parameters (Table 1). Substitutions that altered modulator $\mathrm{pK}_{\mathrm{B}}$ or cooperativity were defined as those that caused a significant change in comparison to the WT receptor $(P$ $<0.05$, one-way ANOVA with multiple comparisons). Selected examples are shown in Figure 2, and all key results are summarized in Figure 3. All concentration-response curves are shown in Supplementary information, Figures S1-S3. Based on these criteria, we identified 7 key amino acid residues that contributed to the binding of the phenylalkylamine modulators (cinacalcet and NPS-2143), F668 ${ }^{2.56}, \mathrm{~F}_{684^{3.36}}, \mathrm{~F} 688^{3.40}, \mathrm{~F} 821^{6.53}$, V833 ${ }^{\text {ECL3 }}$, $\mathrm{E} 837^{7.32}$ and $\mathrm{I} 841^{7.36}$ (Figure 3 and Table 1). In addition to the aforementioned amino acids, several residues were identified that specifically contributed to cinacalcet $\mathrm{pK}_{\mathrm{B}}$ but not to that of NPS-2143, or vice versa (E767 ${ }^{\mathrm{ECL} 2}$, $\mathrm{A} 772^{5.39}, \mathrm{~W} 818^{6.50}, \mathrm{Y} 825^{6.57}$ and $\mathrm{A} 840^{7.35}$ for cinacalcet, and $\mathrm{F} 612^{1.39}$, G670 ${ }^{\mathrm{ECL} 1}, \mathrm{P} 672^{\mathrm{ECL} 1}, \mathrm{R} 680^{3.32}, \mathrm{P} 682^{3.34}$, $\mathrm{L} 776^{5.43}, \mathrm{~F} 832^{\mathrm{ECL} 3}, \mathrm{~S} 834^{\mathrm{ECL} 3}, \mathrm{~V} 838^{7.33}$ and $\mathrm{A} 844^{7.39}$ for NPS-2143; Figure 3 and Table 1).

Informed by the modeling of the phenylalkylamine allosteric ligands, many of the amino acid residues investigated were deemed unlikely to contribute directly to the modulator binding cavity because they face away from the 7TM domain core and instead point outwards towards the membrane. Thus, for the analysis of AC265347, the effects of some of these mutations were not further investigated. Nonetheless, as with both phenylalkylamines, AC-265347 $\mathrm{pK}_{\mathrm{B}}$ was significantly altered by $\mathrm{F} 684^{3.36} \mathrm{~A}, \mathrm{~F} 688^{3.40} \mathrm{~A}, \mathrm{~F} 821^{6.53} \mathrm{~A}$ and $\mathrm{E} 837^{7.32} \mathrm{~A} / \mathrm{D} /$ I substitutions. Like cinacalcet, $\mathrm{AC}-265347 \mathrm{pK}_{\mathrm{B}}$ was also significantly altered by $\mathrm{E} 767^{\mathrm{ECL} 2} \mathrm{~A}, \mathrm{~W} 818^{6.50} \mathrm{~A}$ and $\mathrm{A} 840^{7.35} \mathrm{~V}$ and, like NPS-2143, by $\mathrm{F} 612^{1.39} \mathrm{~A}, \mathrm{~L} 776^{5.43} \mathrm{~A}$ and $\mathrm{A} 844^{7.39} \mathrm{~V}$. In contrast to both phenylalkylamines, $\mathrm{AC}-265347 \mathrm{pK}_{\mathrm{B}}$ was unaltered by Ala substitution at $\mathrm{F} 668^{2.56}$ and $\mathrm{I} 841^{7.36}$, whereas it was altered by $\mathrm{A} 615^{1.42} \mathrm{~V}$, $\mathrm{F} 775^{5.42} \mathrm{~A}$ and $\mathrm{K} 831^{\mathrm{ECL} 3} \mathrm{~A}$. These disparities highlight differences in the binding of the structurally distinct PAMs and NAMs to the CaSR.

Identification of amino acids that mediate cooperativity between $\mathrm{Ca}^{2+}{ }_{0}$ and distinct PAMs or NAMs

Our analytical approach to differentiate the effect of amino acid substitutions on PAM and NAM $\mathrm{pK}_{\mathrm{B}}$ versus cooperativity $(\alpha \beta)$ also enabled analysis of receptor residues that contribute to the transmission of the allosteric effect through the 7TM domain of the CaSR. Mutations that caused a significant change in cooperativity are shown in Figure 3. However, the CaSR responds physiologically to a very narrow range of $\mathrm{Ca}^{2+}{ }_{0}$ concentrations, therefore very small changes in $\mathrm{Ca}^{2+}{ }_{0}$ potency can result in clinically significant effects. For instance, as shown in Table 1 , the estimated $\alpha \beta$ value for cinacalcet in our assays was 2.7 (meaning that it maximally potentiates $\mathrm{Ca}^{2+}$ activity by only 2.7 -fold), yet this PAM is effectively used to treat hyperparathyroidism. Furthermore, changes in $\mathrm{Ca}^{2+}{ }_{\mathrm{o}}$ potency by as low as 1.7 -fold $(\sim 0.5 \mathrm{mM})$ can cause clinically significant effects in human patients [16]. Therefore, although there were more instances of mutations that trended towards altered cooperativity of the PAMs and NAMs within this range of effect (Table 1), statistical significance was not reached. This highlights the difficulties in assessing mutation-induced alterations in allostery at the CaSR. Of note, several mutations resulted in a significant loss of PAM cooperativity with $\mathrm{Ca}^{2+}{ }_{0}$, yet activity in the presence of ambient $\mathrm{Ca}^{2+}{ }_{0}$ was retained (e.g., E $767^{\mathrm{ECL} 2} \mathrm{~A}, \mathrm{~V} 817^{6.49} \mathrm{~A}, \mathrm{~K} 831^{\mathrm{ECL} 3} \mathrm{~A}$ and A $844^{7.39} \mathrm{~V}$; Supplementary information, Figures S1 and S3). This may be due to PAM potentiation of ambient $\mathrm{Mg}^{2+}$ o present in the assay buffer, or it may reflect the ability of the PAMs to directly activate the CaSR [18]. We have previously shown that whereas cinacalcet has very little agonist activity, AC-265347 is an allosteric agonist in its own right [18]. Thus, while cinacalcet loses cooperativity with $\mathrm{Ca}^{2+}{ }_{0}$, it retains its observed activity in the presence of vehicle alone possibly by gaining agonist activity.

Delineation of a common binding pocket for phenylalkylamine allosteric modulators

Molecular models of the CaSR were built based on homology with the $\mathrm{mGlu}_{1}$ and $\mathrm{mGlu}_{5}$ receptors (see Materials and Methods) using alignments shown in Supplementary information, Figure S4. Mutations that perturbed PAM or NAM affinity were mapped onto these models. Each of the corresponding residues faces inwards towards an extended cavity that encompasses the centre to the top of the 7TM domains (Figure 4A). The location of the predicted binding cavity in our CaSR model diverges from previous models due to substantial differences in the alignment of TM3 and 5 with the mGlu receptors in comparison to alignments with the previous template, bovine rhodopsin. For instance, in some earlier models, the binding cavity was composed of two distinct hydrophobic pockets [26, 27]. Nonetheless, our 
Loss in NPS2143 affinity


Gain in AC-265347 affinity
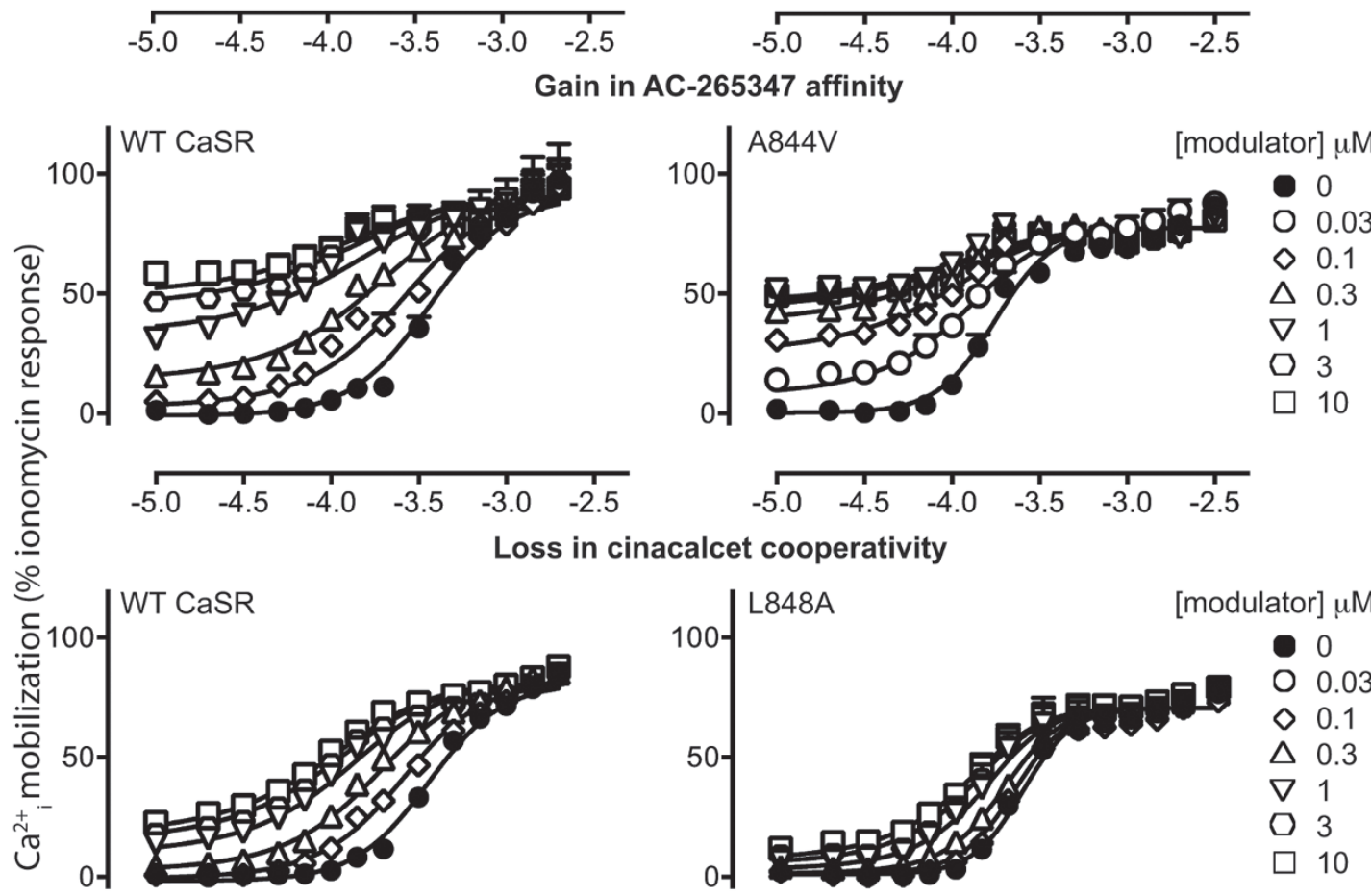

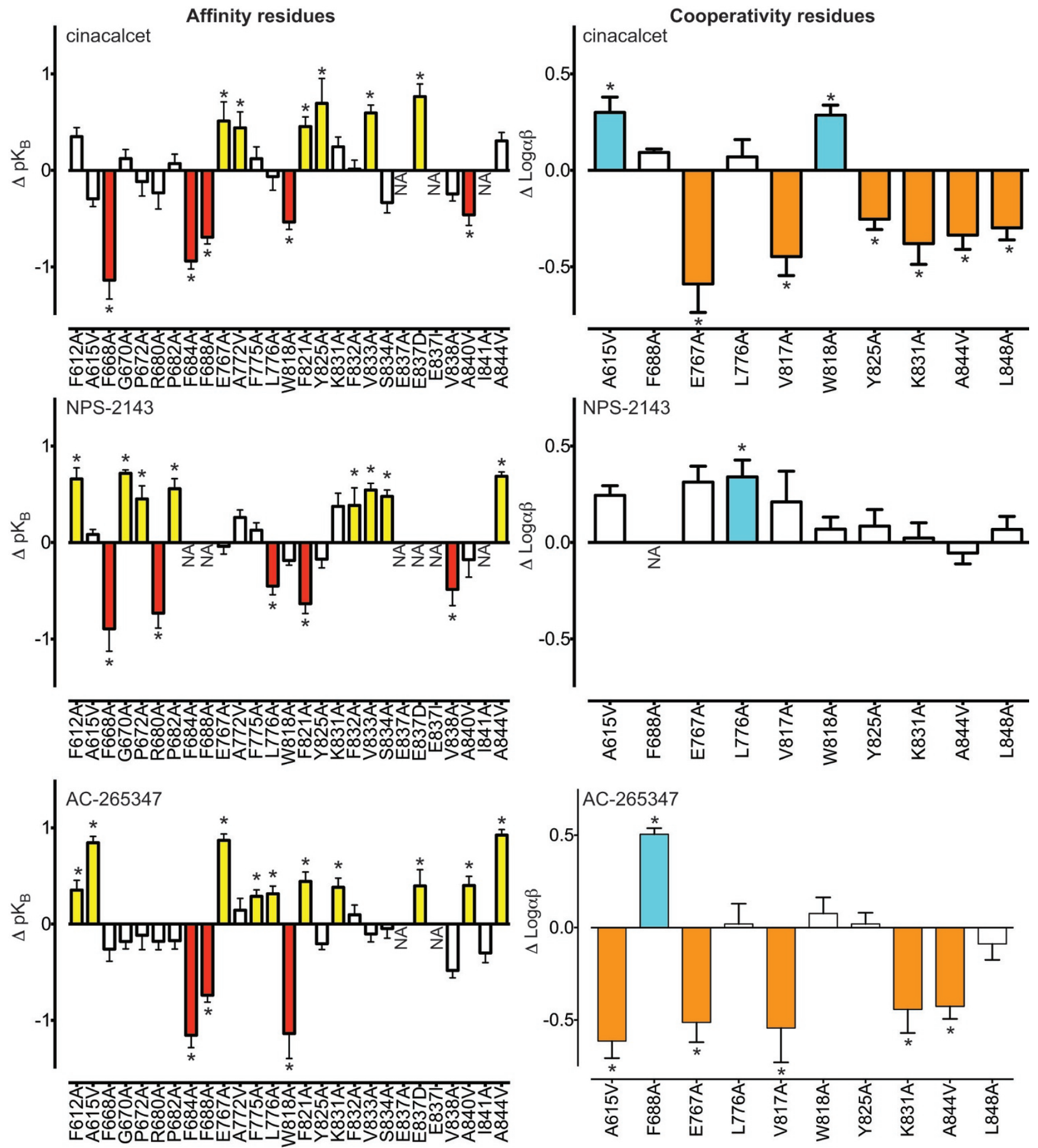

Figure 3 7TM domain mutations alter the $\mathrm{pK}_{\mathrm{B}}$ and cooperativity of PAMs and NAMs at the CaSR. Concentration-response curves to $\mathrm{Ca}^{2+}{ }_{0}$ in the absence and the presence of modulator determined in $\mathrm{Ca}^{2+}{ }_{\mathrm{i}}$ mobilization assays were fitted to an operational model of allosterism (equation 1$)$ to determine the change in $\mathrm{pK}_{\mathrm{B}}\left(\Delta \mathrm{pK}_{\mathrm{B}}\right)$ and cooperativity $(\Delta \mathrm{Log} \alpha \beta)$ of allosteric modulators at the mutant CaSRs in comparison to the WT receptor. Only data for mutations that caused a significant decrease in $\mathrm{pK}_{\mathrm{B}}$ (red bars), increase in $\mathrm{pK}_{\mathrm{B}}$ (yellow bars), decrease in Log $\alpha \beta$ (orange bars) or increase in Log $\alpha \beta$ (turquoise bars) for one or more modulators are shown. White bars represent no significant change in $\mathrm{pK}_{\mathrm{B}}$ or Log $\alpha$. Bars that sit above and below zero represent an increase or decrease in $\mathrm{pK}_{\mathrm{B}}$ or $\alpha \beta$, respectively. NA, no modulator activity. *Significant difference in comparison to the WT ( $P<0.05$, one-way ANOVA with Dunnett's multiple comparisons post test). 



Figure 4 Phenylalkylamines and AC-265347 bind to the CaSR in a distinct manner. (A) Homology model of the CaSR 7TM domains based on the $\mathrm{mGlu}_{5}$ receptor (grey ribbon representation), bound to cinacalcet (purple), NPS-2143 (blue) and AC265347 (green). For clarity, TM4 has been cropped from the images in this panel. Functional effects of mutations were determined by fitting $\mathrm{Ca}^{2+}$ oconcentration-response curves in the absence and the presence of the modulators (Supplementary information, Figures S1-S3) to equation 1 (described in Materials and Methods), and the corresponding amino acid residues where mutations cause a significant decrease or increase in modulator $\mathrm{pK}_{\mathrm{B}}$ are shown in ball and stick representation and are colored red and yellow, respectively. Note that although E837 $7^{7.32}$ is shown in red for cinacalcet because substitution with Ala and lle reduce cinacalcet $\mathrm{pK}_{\mathrm{B}}$, Asp substitution increases cinacalcet $\mathrm{pK}_{\mathrm{B}}$. Hydrogen bonds between $\mathrm{E} 767^{\mathrm{ECL} 2}$, $\mathrm{E} 837^{7.32}$ and cinacalcet, or R680 ${ }^{3.32}$, E837.32 and NPS-2143 are shown as dashed lines. (B) Cross-sectional view through CaSR homology models based on the $\mathrm{mGlu}_{5}$ receptor, highlighting the position of cinacalcet (purple), NPS-2143 (blue) and AC-265347 (green). $\mathrm{E} 767^{\mathrm{ECL2}}$ and $\mathrm{E} 837^{7.32}$ are shown in CPK coloring, where hydrogen is white, carbon is black, nitrogen is blue and oxygen is red.

mutagenesis data are in agreement with previous studies predicting that $\mathrm{F} 668^{2.56}, \mathrm{R} 680^{3.32}, \mathrm{~F} 684^{3.36}, \mathrm{~F} 688^{3.40}$, $\mathrm{E} 767^{\mathrm{ECL} 2}, \mathrm{~L} 776^{5.43}, \mathrm{~W} 818^{6.50}, \mathrm{~F} 821^{6.53}, \mathrm{Y} 825^{6.57}, \mathrm{E} 837^{7.32}$, $\mathrm{V} 838^{7.33}$ and $\mathrm{I} 841^{7.36}$ may contribute to the binding of CaSR modulators [26-29, 33], because mutations at each of these residues resulted in a loss or gain in the affinity of at least one modulator.

Importantly, in our model two negatively charged amino acids, E767 ${ }^{\mathrm{ECL} 2}$ and $\mathrm{E} 837^{7.32}$, face one another at the entrance of the putative binding pocket (Figure 4A and $4 \mathrm{~B})$. Substitutions at $\mathrm{E} 767^{\mathrm{ECL} 2}$ altered PAM $\mathrm{pK}_{\mathrm{B}}$ and those at $\mathrm{E} 837^{7.32}$ altered PAM and NAM $\mathrm{pK}_{\mathrm{B}}$ (Table 1). Substitutions at both residues altered the potency of $\mathrm{Ca}^{2+}{ }_{0}$ (Supplementary information, Table S1). Specifically, introduction of a smaller negatively charged Asp at $\mathrm{E} 837^{7.32}$ increased $\mathrm{Ca}^{2+}{ }_{0}$ potency (Supplementary infor- 
mation, Table $\mathrm{S} 1$ ), enhanced cinacalcet $\mathrm{pK}_{\mathrm{B}}$, but attenuated NPS-2143 $\mathrm{pK}_{\mathrm{B}}$ (Figure 3 and Table 1). In contrast, Ala or Ile substitution of $\mathrm{E} 837^{7.32}$ significantly attenuated phenylalkylamine $\mathrm{pK}_{\mathrm{B}}$ (Figure 3 and Table 1) and $\mathrm{Ca}^{2+}{ }_{0}$ potency (Supplementary information, Table S1). Eliminating $\mathrm{E} 767^{\mathrm{ECL} 2}$ by substitution with $\mathrm{Ala}$, or reversing its charge by substitution with Lys, caused an increase in cinacalcet $\mathrm{pK}_{\mathrm{B}}$ (Supplementary information, Table S1) and $\mathrm{Ca}^{2+}{ }_{0}$ potency [34]. These data are consistent with the mutations stabilizing a more active receptor state that preferentially binds agonists and PAMs. Thus, CaSR signaling is favored by the presence of a negative charge at $\mathrm{E} 837^{7.32}$, but not at E767 $7^{\mathrm{ECL} 2}$. Interestingly, substitution of E767 ${ }^{\text {ECL2 }}$ did not alter NPS-2143 $\mathrm{pK}_{\mathrm{B}}$. However, Ala substitution of $\mathrm{R} 680^{3.32}$, which was also in close proximity to the entrance of the binding cavity, significantly attenuated NPS-2143 $\mathrm{pK}_{\mathrm{B}}$, suggesting that this residue may be more important for the binding of the NAM.

With the above considerations in mind, it seemed possible that $\mathrm{Ca}^{2+}{ }_{0}$, and the phenylalkylamine PAMs and NAMs, provide a counter-ion that offsets the electrostatic repulsion between $\mathrm{E} 767^{\mathrm{ECL} 2}$ and $\mathrm{E} 837^{7.32}$, with $\mathrm{E} 837^{7.32}$ predicted to form a hydrogen bond with the core secondary amine in the modulators (Figure 4A and 4B). Indeed, an interaction between E837 $7^{7.32}$ and the modulators was predicted in previous models [26-29], and is consistent with the homologous hydrogen bond in $\mathrm{mGlu}_{1}$ between $\mathrm{T} 815^{7.32}$ and the terminal amine group on the pyrimidine of the mGlu ${ }_{1}$ NAM, 4-fluoro- $N$-(4-(6-(isopropylamino)pyrimidin-4-yl)thiazol-2-yl)- $N$-methylbenzamide (FITM). E767 $7^{\text {ECL2 }}$ was also predicted to form a hydrogen bond with the same secondary amine in cinacalcet, whereas $\mathrm{R} 680^{3.32}$ seemed more likely to form a hydrogen bond with the hydroxyl group in NPS-2143 (Supplementary information, Figure S5), given the effect of the R680 ${ }^{3.32}$ substitution on NPS-2143 $\mathrm{pK}_{\mathrm{B}}$.

The increase in PAM $\mathrm{pK}_{\mathrm{B}}$, in combination with the molecular modeling, suggests that the interaction between $\mathrm{E} 767^{\mathrm{ECL} 2}$ and cinacalcet is primarily mediated by activation-induced changes in modulator binding. The redistribution of charges upon E767 ${ }^{\mathrm{ECL} 2}$ substitution likely renders it easier for cinacalcet to interact with $\mathrm{E} 837^{7.32}$ and most likely explains the increase in cinacalcet $\mathrm{pK}_{\mathrm{B}}$ upon substitution of $\mathrm{E} 767^{\mathrm{ECL} 2}$. The increase in $\mathrm{Ca}^{2+}{ }_{0}$ potency observed upon substitution of the negative charge at E767 ${ }^{\mathrm{ECL} 2}$ also indicates that this residue restricts activation of the receptor by $\mathrm{Ca}^{2+}{ }_{0}$. To probe this further, we substituted $\mathrm{E} 767^{\mathrm{ECL} 2}$ and $\mathrm{E} 837^{7.32}$ in a CaSR that lacks the entire N-terminal domain and therefore the primary extracellular $\mathrm{Ca}^{2+}{ }_{0}$-binding sites. $\mathrm{Ca}^{2+}{ }_{0}$-mediated signaling is greatly reduced but still operative at this construct [22$25]$, indicating that there is at least one $\mathrm{Ca}^{2+}{ }_{0}$-binding site in the 7TM domain of the CaSR. Each of the constructs was transiently expressed in FlpIn HEK cells and their signaling capacity was evaluated in $\mathrm{Ca}^{2+}{ }_{\mathrm{i}}$ mobilization assays (Supplementary information, Table S2 and Figure S6A). The N-terminally deleted mutants were expressed at $52 \% \pm 7 \%\left(\mathrm{E} 767 \mathrm{~A}^{\mathrm{ECL} 2}\right), 49 \% \pm 5 \%\left(\mathrm{E}^{2} 67 \mathrm{~K}^{\mathrm{ECL} 2}\right), 33 \%$ $\pm 3 \%\left(\mathrm{E}^{2} 37 \mathrm{~A}^{7.32}\right), 20 \% \pm 1 \%\left(\mathrm{E} 837 \mathrm{D}^{7.32}\right)$ or $35 \% \pm 1 \%$ $\left(\mathrm{E} 837 \mathrm{I}^{7.32}\right)$ relative to the $\mathrm{N}$-terminally deleted WT $(n=$ $3)$. There was a small response to $\mathrm{Ca}^{2+}{ }_{0}$ in non-transfected FlpIn HEK cells (Supplementary information, Figure $\mathrm{S} 6 \mathrm{~B})$, although in every instance, the $\mathrm{Ca}^{2+}{ }_{0} E_{\max }$ in transfected cells was significantly different from the $\mathrm{Ca}^{2+}{ }_{0} E_{\max }$ in non-transfected cells $(P<0.05$, extra sum of squares $F$-test). Unlike at the full-length $\mathrm{CaSR}, \mathrm{Ca}^{2+}{ }_{0}$ concentration-response data at the WT and mutant N-terminally truncated receptors were fitted best to the Hill-Langmuir equation with a Hill slope of $1(P<0.05$, extra sum of squares $F$-test). Nonetheless, the fact that $\mathrm{Ca}^{2+}{ }_{0}$-mediated signaling was detectable at each of the N-terminally truncated mutants suggests that E767 $7^{\mathrm{ECL} 3}$ and E837.32 do not provide the sole $\mathrm{Ca}^{2+}{ }_{0}$-binding site in the CaSR 7TM domain.

NPS-2143 exhibited negative allosteric modulation of $\mathrm{Ca}^{2+}{ }_{0}$ signaling at the $\mathrm{N}$-terminally truncated CaSR, confirming its 7TM domain binding site (Supplementary information, Table S2 and Figure S6A). Similar to PAMs tested at $\mathrm{N}$-terminally truncated $\mathrm{mGlu}_{1}$ and $\mathrm{mGlu}_{5}$ receptors $[35,36]$, cinacalcet converted to a direct agonist at the N-terminally truncated CaSR. In fact, at this truncated receptor, cinacalcet-stimulated $\mathrm{Ca}^{2+}{ }_{\mathrm{i}}$ mobilization was identical in the absence or presence of ambient $\mathrm{Ca}^{2+}$ and $\mathrm{Mg}^{2+}{ }_{0}$, suggesting that the direct allosteric agonism of cinacalcet accounts for the majority of its signaling (Supplementary information, Figure S6C). This is unlike at the full-length receptor, where cinacalcet displays little agonism [18], and indicates that the presence of the VFT domain prevents cinacalcet from directly activating the receptor. There was no change in cinacalcet potency at the N-terminally truncated E767 ${ }^{\mathrm{ECL} 2} \mathrm{~A}$ CaSR. This is in contrast to the increase in cinacalcet $\mathrm{pK}_{\mathrm{B}}$ observed at the full-length $\mathrm{E} 767^{\mathrm{ECL} 2} \mathrm{~A} \mathrm{CaSR}$. However, at the N-terminally truncated $\mathrm{E} 767^{\mathrm{ECL} 2} \mathrm{~A}$ CaSR, cinacalcet-stimulated $\mathrm{Ca}^{2+}{ }_{i}$ mobilization was significantly reduced in the absence of ambient $\mathrm{Ca}^{2+}{ }_{0}$ and $\mathrm{Mg}^{2+}$, suggesting that cinacalcet lost its agonism and was a pure PAM. Thus, the $\mathrm{E} 767^{\mathrm{EC}-}$ ${ }^{\mathrm{L} 2} \mathrm{~A}$ substitution prevents the formation of the receptor conformation required for cinacalcet agonism, and it is therefore not surprising that cinacalcet does not bind more favorably to this truncated mutant, as it does at the full-length $\mathrm{E} 767^{\mathrm{ECL} 2} \mathrm{~A}$ receptor.

Similar to the full-length receptor, cinacalcet retained its activity at the N-terminally truncated $\mathrm{E} 837^{7.32} \mathrm{D}$ mu- 
tant, whereas no modulator activity was observed at the $\mathrm{E} 837^{7.32} \mathrm{~A}$ or $\mathrm{E} 837^{7.32} \mathrm{I}$ mutants. This reinforces the conclusion that a negative charge is required at position $837^{7.32}$ for phenylalkylamine binding. Thus, docking studies were performed with the binding site constrained such that the phenylalkylamine secondary amine groups were sufficiently close to form hydrogen bonds with $\mathrm{E} 767^{\mathrm{ECL} 2}$ and $\mathrm{E} 837^{7.32}$.

Previous work combining mutagenesis studies and homology modeling failed to reach a consensus regarding ligand orientation and the role of 7TM domain residues in mediating allosteric ligand binding. Thus, the modulators' phenyl ring could be modeled either dipping into a pocket formed by the 7TM domains [26, 27], or facing towards the extracellular extremities of the 7TM domains and the ECLs $[28,29]$. This is attributable to the low homology between the CaSR and class A GPCRs, which were the only available templates at the time, such that divergent molecular models could all accommodate the limited mutagenesis data available [14-17, 20]. The extensive mutagenesis studies performed herein, however, enabled a more detailed determination of the likely structure of the ligand-binding cavity. In our CaSR mod$\mathrm{el}$, the top of the pocket remains in an open conformation when the phenylalkylamine modulators hydrogen bond with $\mathrm{E} 767^{\mathrm{ECL} 2}$ and $\mathrm{E} 837^{7.32}$ via their secondary amine, allowing the naphthalene group or its substitutions to extend downwards, $\pi$-stacking with $\mathrm{F} 684^{3.36}$ and forming hydrophobic interactions with F668 ${ }^{2.56}, \mathrm{~F} 688^{3.40}$, F821 $1^{6.53}$ and $\mathrm{I} 841^{7.36}$. The phenyl moiety subsequently extends upwards towards the ECL domains, forming hydrophobic interactions between V833 ${ }^{\mathrm{ECL} 3}$ and the fluorophenyl or cyano group on cinacalcet and NPS-2143, respectively (Figure 4A and 4B). Consistent with this are subtle changes in phenylalkylamine $\mathrm{pK}_{\mathrm{B}}$ upon substitution of $\mathrm{V} 833^{\mathrm{ECL} 3}$ (cinacalcet and NPS-2143), F832 ${ }^{\mathrm{ECL} 3}$ and $\mathrm{S} 834^{\mathrm{ECL} 3}$ (NPS-2143). NPS-2143 is also in close proximity to $\mathrm{R} 680^{3.32}$, which could form a hydrogen bond with its hydroxyl group. Supporting this, Ala substitution of R680 $0^{3.32}$ reduces NPS-2143 $\mathrm{pK}_{\mathrm{B}}$ but not that of cinacalcet, which lacks this hydroxyl group.

In addition to amino acid residues that were directly involved in the binding of the phenylalkylamines to the CaSR, F612 $12^{1.39}$, P682 $2^{3.34}$ and A844 ${ }^{7.39}$ were residues that played an indirect role in NPS-2143 binding, presumably by contributing to the overall pocket architecture and influencing ligand entry into, and egress from, the binding cavity. Due to the predicted hydrogen bonding between $\mathrm{E} 767^{\mathrm{ECL} 2}$ and E837 7.32 and NPS-2143, and/or some residues facing away from the predicted binding cavity, NPS-2143 is unlikely to directly interact with the aforementioned residues. This highlights the importance of interpreting mutagenesis data in the context of available structural and molecular modeling information.

\section{Identification of a second allosteric binding pocket for a structurally diverse modulator}

AC-265347 is smaller than cinacalcet and NPS-2143, and minor alterations in its structure can have profound effects on its allosteric activity [37], suggesting a more restricted binding pocket that does not allow for substantial compound modification. Furthermore, unlike the phenylalkylamine PAMs and NAMs, AC-265347 is not positively charged at physiological $\mathrm{pH}$ [37], therefore it does not have the capacity to provide a counter-ion to $\mathrm{E} 767^{\mathrm{ECL} 2}$ and $\mathrm{E} 837^{7.32}$.

Based on the above considerations, AC-265347 was docked into the proposed binding cavity. In our AC265347 model in the absence of $\mathrm{Ca}^{2+}$ o (Figure 4A and 4B), E767 ${ }^{\mathrm{ECL} 2}$ faced away from E837 $7^{7.32}$, and R680.32 occupied the space between the E767 ${ }^{\mathrm{ECL} 2}$ and E837 $7^{7.32}$ (Supplementary information, Figure S5), but this may not be the case in the presence of $\mathrm{Ca}^{2+}{ }_{0}$. Interestingly, Ala substitution of $\mathrm{E} 767^{\mathrm{ECL} 2}$ resulted in a 7-fold increase in AC$265347 \mathrm{pK}_{\mathrm{B}}$. This mutation also causes a gain in receptor function, suggesting that it stabilizes a more active receptor conformation. This indicates that AC-265347 binds more preferably to, and therefore stabilizes, this active receptor state, and this may in part explain the ability of AC-265347, but not cinacalcet, to behave as an allosteric agonist at the full-length CaSR in the absence of cations [18].

Like cinacalcet, AC-265347 was an agonist at the $\mathrm{N}$-terminally truncated CaSR. However, its agonism was enhanced at the N-terminally truncated mutant $\mathrm{E} 767^{\mathrm{ECL} 2} \mathrm{~A}$, as evidenced by an increase in its potency (Supplementary information, Table S2 and Figure S6). This is in contrast to cinacalcet, whose agonism was attenuated by this mutation at the N-terminally truncated receptor. Unlike cinacalcet, AC-265347 may bind concomitantly with $\mathrm{Ca}^{2+}$ 。 to the 7TM domain pocket, enhancing the mutation-induced stabilization of an active receptor state. In contrast to cinacalcet, AC-265347 retained agonist activity at the $\mathrm{N}$-terminally truncated $\mathrm{E} 837^{7.32} \mathrm{~A}$, although its potency was reduced, but like cinacalcet, AC-265347 was ineffective at the N-terminally truncated mutant $\mathrm{E} 837^{7.32} \mathrm{I}$, but retained activity at N-terminally truncated $\mathrm{E} 767^{\mathrm{ECL} 2} \mathrm{~K}$ and $\mathrm{E} 837^{7.32} \mathrm{D}$ mutants.

Collectively, our results demonstrate that the CaSR 7TM domain possesses a large binding cavity that accommodates distinct PAMs and NAMs, spanning a region that resembles the extended cavity in class A and F GPCRs, and is occupied in those cases by both orthosteric and allosteric ligands [38-41]. The similarities in 


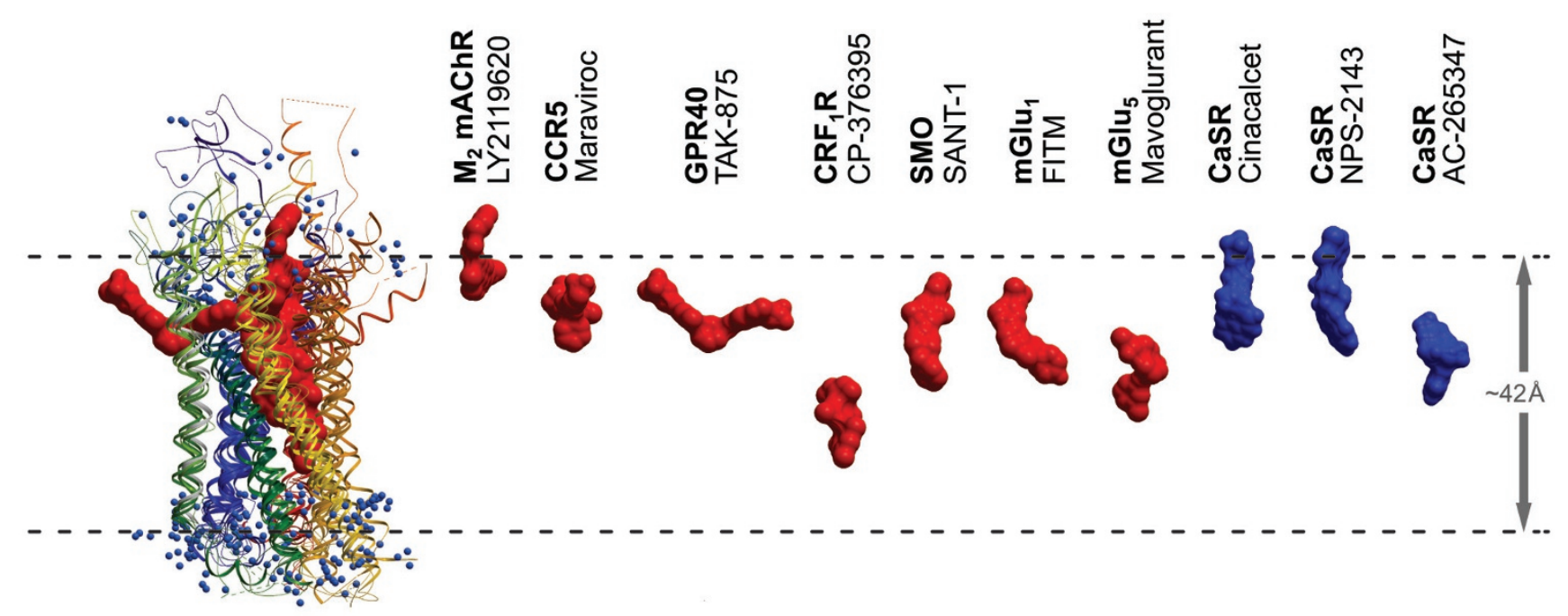

Figure 5 Phenylalkylamine modulators bind to an extended cavity in the CaSR. Comparison between the known binding site location of class $A\left(M_{2}, C C R 5\right.$ and GPR40), B $\left(\mathrm{CRF}_{1} \mathrm{R}\right), \mathrm{C}\left(\mathrm{mGlu}_{1}, \mathrm{mGlu}_{5}\right.$ and $\left.\mathrm{CaSR}\right)$ and $\mathrm{F}$ (SMO) GPCR allosteric modulators. Crystal structures (M $\mathrm{M}_{2}$ PDB: 4MQT; CCR5 PDB: 4MBS; GPR40 PDB: 4PHU; CRF 1 PDB: 4K5Y; SMO PDB: 4O9R; mGlu $_{1}$ PDB: 4OR2 and mGlu ${ }_{5}$ PDB: 4OO9) and CaSR homology models were superimposed using C $\alpha$ atoms of the TM helices and ligands are shown in surface representation, with solved ligand positions represented in red and predicted ligand positions represented in blue. An overlay of the 7TM domains of each of the solved structures with their ligands is shown as a reference (left). Blue spheres shown on the overlay represent the polar side-chain nitrogens of Arg and Lys residues, which tend to cluster at the membrane boundary. Dashed lines indicate the boundaries of the 7TM domains across different GPCR classes. This figure is based on those illustrated in $[56,57]$.

these extended cavities are shown in Figure 5, which depicts the proposed binding poses of CaSR PAMs and NAMs in comparison to representative class A, B, C and F GPCR allosteric ligands from currently solved crystal structures.

\section{Distinct amino acid residues transmit positive coopera-} tivity and bias

As highlighted above, an advantage of our enriched structure-function analysis is the ability to dissect the contribution of mutations to the transmission of cooperativity in addition to the $\mathrm{pK}_{\mathrm{B}}$ of the modulators. Interestingly, only one mutation had a significant effect on the negative allosteric modulation mediated by NPS2143 (Figures 3 and 6, Table 1). The cooperativities of cinacalcet and AC-265347, however, were dependent on a large number of residues, and although some residues were responsible for transmitting cooperativity by both PAMs, particularly in the ECLs (E767 ${ }^{\mathrm{ECL} 2}$ and $\mathrm{K} 831^{\mathrm{ECL} 3}$ ), TM6 (V817 $\left.7^{6.49}\right)$ and TM7 (A844 $\left.{ }^{7.39}\right)$, the locations of other residues differed between the two PAMs. For instance, cinacalcet cooperativity was mediated by unique amino acids located in TM6 (W818 8.50 and Y825 $5^{6.57}$ ) and TM7 $\left(\mathrm{L} 848^{7.43}\right)$, whereas $\mathrm{F} 688^{3.40}$ specifically mediated AC265347 cooperativity. Thus, diverse amino acid residues contributed to the transmission of positive cooperativity by cinacalcet and AC-265347. These residues can be visualized in Figure 6, in which cooperativity-supporting amino acid residues were mapped onto our CaSR models.

The divergence in amino acid residues that transmit the cooperative effects of cinacalcet, AC-265347 and NPS-2143 may in part explain their potential to act as "biased" allosteric modulators of different signaling pathways. For instance, we have previously shown that both cinacalcet and NPS-2143 modulate $\mathrm{Ca}^{2+}{ }_{0}$-mediated $\mathrm{Ca}^{2+}{ }_{i}$ mobilization to a greater extent than ERK1/2 phosphorylation [18-20]. AC-265347, however, preferentially modulates ERK1/2 phosphorylation over $\mathrm{Ca}^{2+}{ }_{i}$ mobilization [18]. Thus, to probe the molecular mechanism behind the distinct biased profile of the modulators, we examined their allosteric interaction with $\mathrm{Ca}^{2+}{ }_{0}$ in pERK1/2 assays at mutants that had differential effects in the $\mathrm{Ca}^{2+}{ }_{\mathrm{i}}$ mobilization assays. In particular, we investigated $\mathrm{A} 615^{1.42} \mathrm{~V}$, which differentially influenced cinacalcet and AC-265347 cooperativity and affinity; F $668^{2.56} \mathrm{~A}$, which reduced cinacalcet and NPS-2143 affinity but had no effect on AC-265347; F688 $8^{3.40} \mathrm{~A}$, which specifically increased AC-265347 cooperativity; W818 ${ }^{6.50} \mathrm{~A}$, which specifically increased cinacalcet cooperativity; 



Figure 6 Distinct amino acids transmit cooperativity mediated by different modulators. Homology models of the 7TM domains and ECLs of the CaSR based on the $\mathrm{mGlu}_{5}$ receptor and the predicted binding pose of each modulator. For clarity, TM4 has been cropped from the images. Residues whose mutations cause a significant decrease or increase in the cooperativity of each modulator are shown in ball and stick representation and are colored orange and turquoise, respectively.

L $848^{7.43} \mathrm{~A}$, which specifically decreased cinacalcet cooperativity; $\mathrm{A} 844^{7.39} \mathrm{~V}$, which decreased the cooperativity of both PAMs; and $\mathrm{L} 776^{5.43} \mathrm{~A}$, which specifically altered NPS-2143 cooperativity. Concentration-response curves revealing allosteric modulation of $\mathrm{Ca}^{2+}{ }_{0}$-mediated ERK1/2 phosphorylation are shown in Supplementary information, Figure S7. Consistent with our previous findings [18-20], cinacalcet and NPS-2143 were biased towards allosteric modulation of $\mathrm{Ca}^{2+}{ }_{\mathrm{i}}$ mobilization at the WT receptor, whereas AC-265347 was biased towards ERK1/2 phosphorylation. This was evidenced by a greater affinity and/or cooperativity in one assay over the other $(P<0.05$, unpaired $t$-test; Table 2$)$. For the most part, the impact of all seven mutations on cinacalcet and NPS-2143 affinity and cooperativity for $\mathrm{Ca}^{2+}{ }_{0}$-mediated ERK1/2 phosphorylation were in agreement with effects observed in $\mathrm{Ca}^{2+}{ }_{\mathrm{i}}$ mobilization assays (Table 2). The exceptions were $\mathrm{F} 688^{3.40} \mathrm{~A}$, which increased cinacalcet affinity in pERK $1 / 2$ assays but decreased its affinity in $\mathrm{Ca}^{2+}{ }_{\mathrm{i}}$ mobilization assays, and $\mathrm{L} 848^{7.43} \mathrm{~A}$, which decreased cinacalcet cooperativity in $\mathrm{Ca}^{2+}{ }_{i}$ mobilization assays yet had no effect in pERK1/2 assays.

In contrast, multiple mutations had differential effects on the affinity and cooperativity of the pERK1/2-biased modulator AC-265347. L $776^{5.43} \mathrm{~A}$ and $\mathrm{L} 848^{7.43} \mathrm{~A}$, which had little to no effect on $\mathrm{AC}-265347 \mathrm{pK}_{\mathrm{B}}$ in $\mathrm{Ca}^{2+}{ }_{\mathrm{i}}$ mobilization assays, significantly increased AC-265347 $\mathrm{pK}_{\mathrm{B}}$ in pERK1/2 assays (Table 2 and Figure 7). Conversely, $\mathrm{F} 688^{3.40} \mathrm{~A}$ and $\mathrm{W} 818^{6.50} \mathrm{~A}$, which significantly reduced
AC-265347 $\mathrm{pK}_{\mathrm{B}}$ in $\mathrm{Ca}^{2+}{ }_{\mathrm{i}}$ mobilization assays, had no effect or a reduced impact on $\mathrm{AC}-265347 \mathrm{pK}_{\mathrm{B}}$ in pERK1/2 assays. $\mathrm{L} 776^{5.43} \mathrm{~A}$ increased AC-265347 cooperativity with $\mathrm{Ca}^{2+}{ }_{0}$, an effect specific to pERK1/2 signaling. Similarly, W818 ${ }^{6.50} \mathrm{~A}$ decreased AC-265347 cooperativity with $\mathrm{Ca}^{2+}{ }_{\mathrm{o}}$ in $\mathrm{pERK} 1 / 2$ assays, despite this mutation having no effect on the cooperativity between $\mathrm{Ca}^{2+}{ }_{0}$ and $\mathrm{AC}-265347$ in $\mathrm{Ca}^{2+}{ }_{\mathrm{i}}$ mobilization assays. Conversely, $\mathrm{A} 615^{1.42} \mathrm{~V}$ had no effect on AC-265347 cooperativity in pERK1/2 assays, despite significantly decreasing cooperativity with $\mathrm{Ca}^{2+}{ }_{0}$ in $\mathrm{Ca}^{2+}{ }_{\mathrm{i}}$ mobilization assays. The most striking differential effect of a single mutation on AC-265347 cooperativity with $\mathrm{Ca}^{2+}{ }_{0}$ was $\mathrm{F} 688^{3.40} \mathrm{~A}$, which increased $\log \alpha \beta$ in $\mathrm{Ca}^{2+}{ }_{\mathrm{i}}$ mobilization assays but decreased $\log \alpha \beta$ in $\mathrm{pERK} 1 / 2$ assays. Collectively, these data support the concept that different allosteric modulator chemotypes stabilize distinct receptor conformations, giving rise to biased modulation, as evidenced by the differential effects of mutants on modulator affinity depending on the measure of receptor activity. Moreover, these data provide the first insights into the key amino acids that differentially transmit AC-265347 cooperativity, compared to cinacalcet, resulting in bias to ERK1/2 phosphorylation over $\mathrm{Ca}^{2+}{ }_{i}$ mobilization.

\section{Discussion}

The current study has combined mutagenesis, analytical pharmacology and molecular modeling to provide 

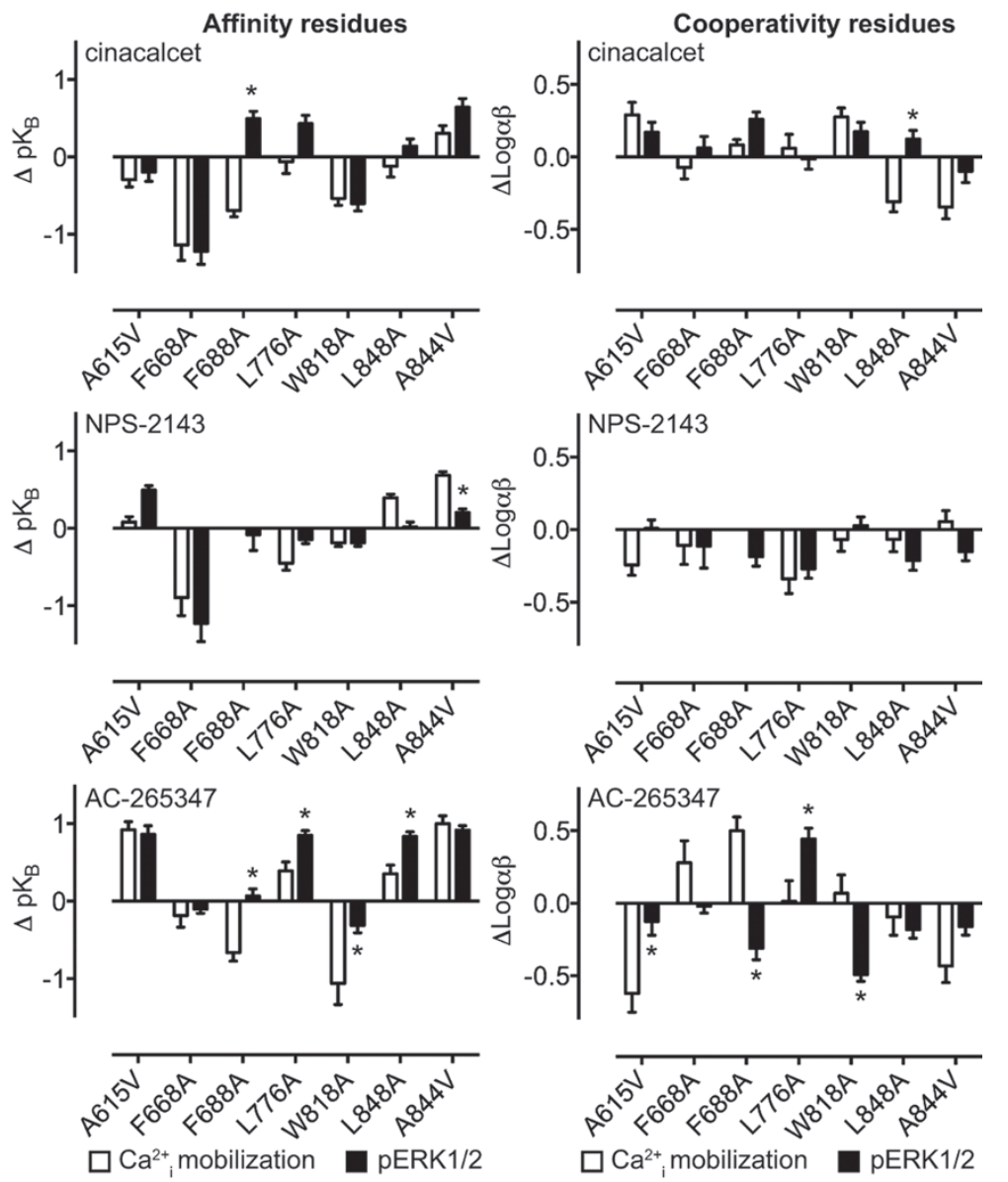

Figure 7 Distinct amino acids contribute to biased allosteric modulation by PAMs and NAMs. White bars depict $\Delta \mathrm{pK} \mathrm{B}_{\mathrm{B}}$ or $\Delta \log \alpha \beta$ between WT and mutants determined in $\mathrm{Ca}^{2+}{ }_{i}$ mobilization assays, and black bars depict those determined in pERK1/2 assays. Asterisks mark those mutants where there was a significant difference in the $\Delta p K B$ or $\Delta$ Log $\alpha \beta$ for one mutant between $\mathrm{Ca}^{2+}{ }_{\mathrm{i}}$ mobilization and pERK1/2 assays $(P<0.05$, multiple $t$-tests).

Table 2 Functional affinity $\left(\mathrm{pK}_{\mathrm{B}}\right)$ and cooperativity $(\log \alpha \beta)$ parameters for CaSR modulators determined in $\mathrm{pERK} 1 / 2$ assays as described in Materials and Methods. Data are mean \pm SEM from the indicated number of independent experiments $(n)$.

\begin{tabular}{|c|c|c|c|c|c|c|c|c|c|}
\hline & \multicolumn{2}{|c|}{ Cinacalcet } & \multicolumn{3}{|c|}{ NPS-2143 } & \multicolumn{4}{|c|}{ AC-265347 } \\
\hline & $\mathrm{pK}_{\mathrm{B}}$ & $\log \alpha \beta(\alpha \beta)$ & $n$ & $\mathrm{pK}_{\mathrm{B}}$ & $\log \alpha \beta(\alpha \beta)$ & $n$ & $\mathrm{pK}_{\mathrm{B}}$ & $\log \alpha \beta(\alpha \beta)$ & \\
\hline WT & $6.52 \pm 0.07$ & $0.12 \pm 0.05^{\#}(1.3)$ & 5 & $6.36 \pm 0.04^{\#}$ & $-0.21 \pm 0.04(0.62)$ & 4 & $6.68 \pm 0.05^{\#}$ & $0.65 \pm 0.06(4.5)$ & \\
\hline $\mathrm{A} 615^{1.42} \mathrm{~V}$ & $6.52 \pm 0.07$ & $0.29 \pm 0.05^{\#}(1.9)$ & 4 & $6.86 \pm 0.04 *$ & $-0.20 \pm 0.04^{\#}(0.63)$ & 4 & $7.54 \pm 0.10^{* \#}$ & $0.52 \pm 0.07^{\# \wedge}(3.3)$ & \\
\hline $\mathrm{F} 668^{2.56} \mathrm{~A}$ & $5.30 \pm 0.15^{*}$ & $0.18 \pm 0.07(1.5)$ & 4 & $5.15 \pm 0.23^{* \#}$ & $-0.32 \pm 0.15(0.48)$ & 4 & $6.57 \pm 0.05^{\#}$ & $0.63 \pm 0.05(4.3)$ & \\
\hline $\mathrm{F} 688^{3.40} \mathrm{~A}$ & $7.02 \pm 0.07 *^{\# \wedge}$ & $0.38 \pm 0.02 *(2.4)$ & 4 & $6.28 \pm 0.20^{\#}$ & $-0.02 \pm 0.05(0.95)$ & 4 & $6.74 \pm 0.08^{\# \wedge}$ & $0.34 \pm 0.05^{* \# \wedge}(2.2)$ & \\
\hline $\mathrm{L} 776^{5.43} \mathrm{~A}$ & $6.95 \pm 0.08^{* \#}$ & $0.11 \pm 0.05^{\#}(1.3)$ & 5 & $6.22 \pm 0.05$ & $-0.48 \pm 0.05^{*}(0.33)$ & 4 & $7.53 \pm 0.06^{*^{*} \wedge}$ & $1.09 \pm 0.07^{* * \wedge}(12.3)$ & \\
\hline $\mathrm{W} 818^{6.50} \mathrm{~A}$ & $5.92 \pm 0.06^{*}$ & $0.29 \pm 0.04^{\#}(1.9)$ & 5 & $6.18 \pm 0.04$ & $-0.18 \pm 0.05(0.66)$ & 4 & $6.36 \pm 0.10^{* *^{\#}}$ & $0.16 \pm 0.05^{* \# \wedge}(1.4)$ & \\
\hline $\mathrm{A} 844^{7.39} \mathrm{~V}$ & $7.17 \pm 0.09^{* \#}$ & $0.02 \pm 0.06(1.0)$ & 5 & $6.57 \pm 0.05^{\# \wedge}$ & $-0.36 \pm 0.05(0.44)$ & 4 & $7.59 \pm 0.06^{* \#}$ & $0.49 \pm 0.06^{\#}(3.0)$ & $\gamma$ \\
\hline $\mathrm{L} 848^{7.43} \mathrm{~A}$ & $6.66 \pm 0.07^{\#}$ & $0.24 \pm 0.04^{\wedge}(1.7)$ & 5 & $6.38 \pm 0.06^{\#}$ & $-0.42 \pm 0.06^{*}(0.38)$ & 4 & $7.51 \pm 0.06^{* \# \wedge}$ & $0.47 \pm 0.06(3.0)$ & 5 \\
\hline
\end{tabular}

*Denotes significantly different from WT value determined in the same assay $(P<0.05$, one-way ANOVA with Dunnett's multiple comparisons post test).

${ }^{\#}$ Significantly different from $\mathrm{pK}_{\mathrm{B}}$ or $\log \alpha \beta$ determined in $\mathrm{Ca}^{2+}{ }_{\mathrm{i}}$ mobilization assays $(P<0.05$, unpaired $t$-test $)$.

${ }^{\wedge} \Delta \mathrm{pK}_{\mathrm{B}}$ or $\Delta \log \alpha \beta$ between WT and mutant is significantly different in $\mathrm{Ca}^{2+}{ }_{\mathrm{i}}$ mobilization versus pERK1/2 assays $(P<0.05,2$-way ANOVA with Sidak's multiple comparisons post-test). 
structural and functional insights into allosteric modulation of the CaSR 7TM domain in the absence of direct structure determination. It identifies an extended 7TM domain cavity that can accommodate multiple binding sites for structurally diverse synthetic allosteric modulators, determines a putative $7 \mathrm{TM}$ domain $\mathrm{Ca}^{2+}{ }_{0}$-binding site, and establishes discrete networks of amino acids that transmit cooperativity and biased modulation mediated by distinct modulators. Of note, all these findings were determined in the context of the full-length (functional) receptor, whereas all existing structures of class $\mathrm{C}$ receptors to date are only of either VFT [42-45] or 7TM domains $[30,31]$. Collectively, this information adds to our understanding of allostery at the CaSR and of how allosteric modulators target class C GPCRs.

The extended binding cavity identified in the CaSR resembles a cavity that accommodates the $\mathrm{mGlu}_{1}$ and $\mathrm{mGlu}_{5}$ receptor allosteric modulators. However, the phenylalkylamine-binding site extends up towards the ECLs, whereas FITM binds to $\mathrm{mGlu}_{1}$ in a position that is analogous to the deeper orthosteric site of class A GPCRs, and mavoglurant ( $\mathrm{mGlu}_{5}$ ) and AC-265347 (CaSR) bind even further down in the 7TM domains [30,31,38] (Figure 5). Furthermore, the top of the CaSR binding pocket is predicted to adopt an open conformation when the phenylalkylamines hydrogen bond with $\mathrm{E} 767^{\mathrm{ECL} 2}$ and E837 $7^{7.32}$ via their secondary amine, which is in contrast to the more restricted binding pocket in the mGlu receptors $[30,31]$. These findings indicate great diversity in the binding mode of allosteric modulators even within class C GPCRs.

It is noteworthy that AC-265347 exhibits distinct pharmacological properties in comparison to phenylalkylamine PAMs. For instance, AC-265347 is an (allosteric) agonist in its own right, whereas cinacalcet cannot activate the full-length CaSR in the absence of $\mathrm{Ca}^{2+}{ }_{0}$ or $\mathrm{Mg}^{2+}$ o [18]. Interestingly, a similar finding has been reported for $\mathrm{mGlu}_{4}$ receptor PAMs, with those predicted to bind more deeply in the receptor cavity being more efficient at stabilizing active states than PAMs that bind closer to the extracellular vestibule [46].

In contrast to previous studies at the CaSR, the current approach to differentiating mutational effects on affinity versus cooperativity provides a more detailed understanding of receptor regions involved in ligand binding versus transmission of cooperativity. Mutation-induced alterations in cooperativity, but not affinity, are only apparent when appropriate analyses are undertaken to fully quantify these effects. Mutation-associated changes in the potency of allosteric ligands to modulate the activity of an agonist at a single concentration have been interpreted as alterations in modulator binding affinity
[46], but assumptions based on misinterpretations of potency changes may underlie flawed predictions of the mode of binding of GPCR ligands. Our approach has also enabled us to understand how AC-265347 may preferentially modulate distinct intracellular signaling pathways in comparison to phenylalkylamine PAMs [18]; the distinct amino acids that mediate cinacalcet versus AC-265347 positive cooperativity highlight differences in the conformational states favored by these two PAMs. These different conformational states may be responsible for the preference in receptor coupling to diverse pathways in the presence of each PAM. In agreement, we also identified residues that contributed differently to the transmission of AC-265347 cooperativity in $\mathrm{Ca}^{2+}{ }_{\mathrm{i}}$ mobilization versus pERK1/2 assays, providing the first structural insights into the molecular basis for the biased modulation elicited by AC-265347 at the CaSR. This indicates that in addition to the specific ligand-receptor interactions governing affinity, the residues that mediate cooperativity are also critical for its pharmacological properties. Indeed, although the predicted binding poses of the phenylalkylamine PAM, cinacalcet and the NAM, NPS-2143 were almost identical, they mediate opposing directions of cooperativity with $\mathrm{Ca}^{2+}{ }_{0}$ (i.e., positive versus negative). Intriguingly, only one mutation significantly altered the negative allosteric modulation mediated by NPS-2143, suggesting that whereas PAMs may favor the transition to an active receptor state via movement of numerous amino acid side-chains, NPS-2143 obstructs this transition, holding the receptor in an inactive state. This is not surprising if NPS-2143 is predicted to be locked into position through hydrogen bond interactions that do not exist with the PAMs, such as between its hydroxyl group and $\mathrm{R} 680^{3.32}$. This rigid NPS-2143 binding pose most likely restricts movement of CaSR 7TM domains, whereas PAMs allow more flexibility.

The CaSR remains an important drug target not only for diseases in which modulating its activity has proven therapeutic benefits, such as treatment of primary and secondary hyperparathyroidism, but also for diseases in which the receptor's full therapeutic potential are yet to be established, including neonatal severe hyperparathyroidism, familial hypocalciuric hypercalcemia, autosomal dominant hypocalcemia, hypercalcemia of malignancy, pancreatitis, diabetes mellitus, cancer, bone disease, cardiovascular disease, Alzheimer's disease, gastrointestinal disorders and airway inflammation [21, 47, 48]. The encouraging prospect of using CaSR therapeutics to treat numerous and varied disease states requires the rational design of drugs with desired pharmacological activity. The current study provides new insight into how PAMs and NAMs bind $\mathrm{Ca}^{2+}{ }_{0}$ within the 7TM domains of 
the CaSR and transmit cooperativity. This information is pivotal to unraveling the molecular mechanisms that may underlie modulator in vitro and in vivo properties. It suggests that allosteric pharmacology may be directed by targeting drugs of pre-defined structures to distinct binding sites in class C GPCRs and/or controlling modulator cooperativity via specific amino acid networks. This knowledge may facilitate rational structure-based design of novel ligands whose therapeutic properties could be optimized by fine-tuning their molecular activity.

\section{Materials and Methods}

\section{Materials}

Dulbecco's modified Eagle's medium (DMEM), blasticidin S $\mathrm{HCl}$ and $\mathrm{FBS}$ certified to contain $<10 \mathrm{ng} / \mathrm{ml}$ tetracycline were obtained from Invitrogen (Carlsbad, CA, USA), whilst hygromycin B was from Roche (Mannheim, Germany). The Flp-In ${ }^{\text {TM }}$ TREx $^{\text {TM }}$ Human Embryonic Kidney (HEK) 293 cells and Fluo-4 AM (acetoxymethyl ester) were purchased from Invitrogen. AF647-conjugated 9E10 antibody was prepared in-house as described previously [18]. Quikchange mutagenesis kits were from Agilent Technologies (Santa Clara, CA, USA). Cinacalcet $\mathrm{HCl}$ was prepared as described previously [19]. NPS-2143 was either made in-house [19] or purchased from Selleck Chemicals (Houston, TX, USA). AC-265347 and all other chemicals were from Sigma Aldrich (St Louis, MI, USA).

\section{Choice of PAMs and NAMs}

Cinacalcet is a prototypical phenylalkylamine PAM and the only calcimimetic currently approved for the treatment of hyperparathyroidism. AC-265347 is a chemically distinct PAM that displays in vitro and in vivo pharmacology that differs from cinacalcet, including a discrete biased modulation profile and diverse tissue-specific effects $[14,18]$. NPS-2143 is a prototypical CaSR NAM with a well-characterized in vitro and in vivo pharmacological profile $[49,50]$.

Generation and maintenance of cell lines expressing the WT and mutant CaSRs

C-myc-tagged CaSR in pcDNA ${ }^{\mathrm{TM}} 5 / \mathrm{fr} / \mathrm{TO}$ and the N-terminally truncated CaSR in pcDNA3.1+ have been described previously [19, $25,34]$. The N-terminally truncated CaSR cDNA was modified to increase its cell surface expression. First, the following sense and antisense primers were annealed and amplified with Taq polymerase in 4 short PCR cycles to generate a fragment containing a Kozak consensus sequence, followed by the influenza hemagglutinin signal peptide sequence, a double c-myc tag, an EcoRV restriction site and a $3^{\prime}$ poly-A overhang; sense $5^{\prime}$-caccatgaagacgatcatcgccetgagctacatcttctgcctggtattcgecgagcaaaagctcatttc- $3^{\prime}$, antisense $5^{\prime}$-gatatccaacaagtcctcttcagaaatgagcttttgctccaacaagtcctcttcagaaatgagctttcctcgg-3'. The PCR fragment was cloned into pcDNA3.1/ V5His-TOPO-TA, using the TOPO-TA isomerase cloning kit according to the manufacturer's instructions (Invitrogen). A ccdB Gateway ${ }^{\circledR}$ vector conversion cassette (Invitrogen) was cloned into the vector at the $E c o R V$ site to create a Gateway ${ }^{\circledR}$ destination vector. The N-terminally truncated CaSR was subsequently amplified by PCR using the following sense and antisense primers to remove the ATG initiation codon and introduce attB sites for Gateway (Invitrogen) cloning; sense 5'-ggggacaagtttgtacaaaaaagcaggcttcaacgggaccgagggccca-3', antisense 5'-ggggaccactttgtacaagaaagctgggtcctatccaaggctgctgga-3'. The resultant PCR product was cloned into pDONR201 (Invitrogen) and subcloned into the Gateway pcDNA3.1+ vector using Gateway cloning (Invitrogen). For generation of mutant receptors, c-myc-tagged CaSR or c-myc-tagged $\mathrm{N}$-terminally truncated CaSR were subjected to Quikchange ${ }^{\circledR}$ II site-directed mutagenesis (Agilent Technologies) according to the manufacturer's instructions. Primers for mutagenesis are listed in Supplementary information, Table S3. All constructs were sequenced in both directions to verify their integrity. Protocols for the generation of FlpIn HEK293 TRex cell lines expressing the full-length WT and full-length mutant human CaSR have been described previously $[20,34]$. These cells were maintained in DMEM containing 5\%-10\% FBS, $200 \mu \mathrm{g} / \mathrm{ml}$ hygromycin B and $5 \mu \mathrm{g} / \mathrm{ml}$ blasticidin $\mathrm{S} \mathrm{HCl}$. N-terminally truncated WT and mutant CaSRs were transiently expressed in FlpIn HEK293 TRex cells following transfection with $15 \mu \mathrm{g}$ DNA and lipofectamine 2000 in a $T 75 \mathrm{~cm}^{2}$ flask according to the manufacturer's instructions, using a ratio of 1:4 DNA:lipofectamine 2000. Twenty-four hours following transfection, cells were transferred to 96 -well plates and assays were performed $24 \mathrm{~h}$ after cell plating.

\section{Flow cytometry analysis for receptor expression}

FlpIn HEK293 TRex cells stably expressing full-length c-myc CaSRs (c-myc epitope inserted between amino acids D371 and T372 [19]) or transiently expressing N-terminally truncated c-myc CaSRs (c-myc at the N-terminus) were seeded in a 96-well plate at a density of 80000 cells per well in DMEM containing $100 \mathrm{ng} /$ $\mathrm{ml}$ tetracycline and incubated overnight at $37^{\circ} \mathrm{C}$. On the next day, cells were harvested with phosphate-buffered saline (PBS; 137 $\mathrm{mM} \mathrm{NaCl}, 2.7 \mathrm{mM} \mathrm{KCl}, 4.3 \mathrm{mM} \mathrm{Na} \mathrm{HPO}_{4}, 1.5 \mathrm{mM} \mathrm{KH}_{2} \mathrm{PO}_{4}, \mathrm{pH}$ 7.4) supplemented with $0.1 \%$ BSA, 2 mM EDTA and $0.05 \% \mathrm{NaN}_{3}$ (washing buffer) and transferred to wells of a 96-well v-bottom plate, centrifuged for $3 \mathrm{~min}$ at $350 \times \mathrm{g}, 4{ }^{\circ} \mathrm{C}$ and resuspended in $100 \mu \mathrm{l}$ blocking buffer (PBS, 5\% BSA, $2 \mathrm{mM}$ EDTA and $0.05 \%$ $\mathrm{NaN}_{3}$ ). Cells were incubated for $30 \mathrm{~min}$ in blocking buffer and subsequently incubated for $1 \mathrm{~h}$ with an AF647-conjugated 9E10 antibody [18], diluted in blocking buffer at $1 \mu \mathrm{g} / \mathrm{ml}$. Cells were subsequently washed with washing buffer and resuspended in washing buffer with Sytox blue (1:2 000; Molecular Probes). The fluorescence signal was quantified using a FACS Canto (Becton Dickinson).

\section{$\mathrm{Ca}^{2+}{ }_{i}$ mobilization assays}

Cells were seeded in a clear 96-well plate coated with poly-D-lysine $(50 \mu \mathrm{g} / \mathrm{ml})$ at 80000 cells per well and incubated overnight in the presence of $100 \mathrm{ng} / \mathrm{ml}$ tetracycline. On the following day, cells were washed with assay buffer $(150 \mathrm{mM} \mathrm{NaCl}, 2.6 \mathrm{mM}$ $\mathrm{KCl}, 1.18 \mathrm{mM} \mathrm{MgCl}_{2}, 10 \mathrm{mM}$ D-glucose, $10 \mathrm{mM}$ HEPES, $0.1 \mathrm{mM}$ $\mathrm{Ca}^{2+}{ }_{0}, 0.5 \% \mathrm{BSA}$ and $4 \mathrm{mM}$ probenecid at $\mathrm{pH}$ 7.4) and loaded with Fluo-4 AM ( $1 \mu \mathrm{M}$ in assay buffer) for $1 \mathrm{~h}$ at $37^{\circ} \mathrm{C}$.

Cells were washed with assay buffer prior to the addition of fresh assay buffer. In functional interaction studies between $\mathrm{Ca}^{2+}{ }_{\mathrm{o}}$ and NPS-2143, NPS-2143 was preincubated with the cells for 20-30 min prior to the addition of $\mathrm{Ca}^{2+}{ }_{0}$. In functional interaction studies between $\mathrm{Ca}^{2+}{ }_{0}$ and the calcimimetics, the modulators were 
coadded with $\mathrm{Ca}^{2+}{ }_{0}$. In all assays measuring agonist-stimulated receptor signaling events, each well was treated with a single concentration of agonist and/or modulator. The release of $\mathrm{Ca}^{2+}{ }_{i}$ was measured at $37^{\circ} \mathrm{C}$ using a Flexstation ${ }^{\circledR} 1$ or 3 (Molecular Devices; Sunnyvale, CA, USA). Fluorescence was detected for $60 \mathrm{~s}$ at 485-nm excitation and 525-nm emission, and the peak $\mathrm{Ca}^{2+}{ }_{\mathrm{i}}$ mobilization response ( $\sim 12 \mathrm{~s}$ after agonist addition) was used for the subsequent determination of the agonist response. Relative peak fluorescence units were normalized to the fluorescence stimulated by $1 \mu \mathrm{M}$ ionomycin to account for differences in cell number and loading efficiency.

\section{pERK1/2 assays}

Cells were seeded in a clear 96-well plate coated with poly-D-lysine $(50 \mu \mathrm{g} / \mathrm{ml})$ at 80000 cells per well and incubated overnight in the presence of $100 \mathrm{ng} / \mathrm{ml}$ tetracycline. On the following day, cells were washed with PBS, and serum-free DMEM containing $16 \mathrm{mM}$ HEPES and $0.1 \mathrm{mM} \mathrm{Ca}^{2+}{ }_{0}$ was added to wells. For assays with cinacalcet and AC-265347, vehicle or agonist $\left(\mathrm{Ca}^{2+}{ }_{0}\right)$ with or without modulator was coadded to wells and incubated for $2.5 \mathrm{~min}$ (the time determined in prior assays for $\mathrm{pERK} 1 / 2$ to peak) at $37{ }^{\circ} \mathrm{C}$. For assays with NPS-2143, the modulator was preincubated with the cells for $20 \mathrm{~min}$ prior to agonist addition. All data were normalized to the response stimulated by $3 \mathrm{mM} \mathrm{Ca}^{2+}{ }_{0}$ in the absence of modulator. pERK1/2 was determined using the SureFire pERK1/2 assay kit (kindly donated by Dr Michael Crouch, TGR biosciences, Adelaide) employing AlphaScreen technology (PerkinElmer) according to the manufacturer's instructions.

\section{Data analysis}

All nonlinear regression analysis was performed using GraphPad Prism 6 (GraphPad Software, San Diego, CA, USA). Parametric measures of potency, affinity and cooperativity were estimated as logarithms [51]. Interaction experiments between $\mathrm{Ca}^{2+}{ }_{0}$ and the allosteric modulators were fitted to the following operational model of allosterism [17].

Equation 1:

$$
E=\frac{E_{\mathrm{m}}\left(\tau_{\mathrm{A}}[\mathrm{A}]\left(K_{\mathrm{B}}+\alpha \beta[\mathrm{B}]\right)+\tau_{\mathrm{B}}[\mathrm{B}] K_{\mathrm{A}}\right)^{\mathrm{n}}}{\left([\mathrm{A}] K_{\mathrm{B}}+K_{\mathrm{A}} K_{\mathrm{B}}+K_{\mathrm{A}}[\mathrm{B}]+\alpha[\mathrm{A}][\mathrm{B}]\right)^{\mathrm{n}}+\left(\tau_{\mathrm{A}}[\mathrm{A}]\left(K_{\mathrm{B}}+\alpha \beta[\mathrm{B}]\right)+\tau_{\mathrm{B}}[\mathrm{B}] K_{\mathrm{A}}\right)^{n},}
$$

where $\tau_{\mathrm{A}}$ and $\tau_{\mathrm{B}}$ denote the efficacy of orthosteric and allosteric ligands, respectively, $\alpha$ and $\beta$ denote allosteric effects on orthosteric ligand-binding affinity and efficacy, respectively, which were estimated as a composite $\alpha \beta$ value. $K_{\mathrm{A}}$ and $K_{\mathrm{B}}$ are the functional affinities of orthosteric and allosteric ligands, respectively, and [A] and $[\mathrm{B}]$ denote their respective concentrations. $E_{\mathrm{m}}$ is the maximal possible system response and $n$ is the slope factor of the transducer function.

\section{Statistics}

Statistical differences between the $\mathrm{Ca}^{2+}{ }_{0} \mathrm{pEC}_{50}$, or PAM and NAM $\mathrm{pK}_{\mathrm{B}}$ and $\log \alpha \beta$ at the WT versus the mutant receptors, were determined by one-way ANOVA with Dunnett's multiple comparisons post test, where significance was considered when $P<0.05$. Statistical differences between the expression levels of the WT versus mutant receptors were determined by the $95 \%$ confidence interval (CI), where only CIs excluding $100 \%$ were considered significant.

\section{Mutagenesis, molecular modeling and docking studies}

Our initial mutagenesis approach was designed to evaluate the role of residues that were predicted to contribute to phenylalkylamine PAM and NAM binding in earlier molecular modeling studies [26-29, 33]. Subsequent to these experiments, the structures of $\mathrm{mGlu}_{1}$ (PDB: 2OR2 [31]) and $\mathrm{mGlu}_{5}$ (PDB: 4009 [30]) were solved and were used as templates to build homology models of the CaSR's 7TM domain using the ICM software package [52] (Molsoft; San Diego, CA, USA). As sequence identity between the 7TM domains of the CaSR and the mGlu receptors is low ( $29 \%$ and $33 \%$ homology with $\mathrm{mGlu}_{1}$ and $\mathrm{mGlu}_{5}$, respectively), ICM-generated alignments were inspected manually; the TM7 alignment was adjusted to improve residue correspondence and orient polar residues known to be involved in ligand binding (e.g., E837 7.32 ) towards the binding pocket.

Initial CaSR models were built by threading the CaSR sequence onto the mGlu template coordinates according to the alignment. For stretches of $<12$ residues that aligned against gaps in the template, the algorithm first searched a library of PDB fragments for candidate conformations and then optimized them by extensive conformational sampling; insertions of 12 or more residues were omitted from the modeling procedure. Residue side-chains in the models were refined with $5 \times 10^{5}$ steps of Monte Carlo optimization in internal coordinates. Following this refinement, both backbone and side-chains were locally minimized in the presence of distance restraints that mimicked the hydrogen bonding within the model and maintained the integrity of its secondary and tertiary structure in the course of minimization.

The mGlu crystal structures were solved in a presumed inactive conformation because they are bound to NAMs, and are therefore not ideal for docking PAMs. Therefore, for ligand docking, both CaSR models were considered as a conformational ensemble, and were used interchangeably depending on the best docking scores for individual modulators. The approximate location of the binding cavity was therefore inherited from the crystal structures of $\mathrm{mGlu}_{1}$ and $\mathrm{mGlu}_{5}$. Candidate regions of the cavity were studied in terms of their pharmacophore-like binding properties [53] and a graphical representation of where ligand atom centres should be placed for optimal interactions with the receptor was built using ICM Ligand Editor [54]. Based on the alteration of PAM and NAM $\mathrm{pK}_{\mathrm{B}}$ caused by mutations at the two acidic residues, E767 ${ }^{\mathrm{ECL} 2}$ and $\mathrm{E} 837^{7.32}$, these residues constituted a likely site for phenylalkylamine binding. Therefore, the phenylalkylamines were docked by extensive conformational sampling of the ligand and the residue side-chains lining the pocket, while maintaining adequate distance to allow hydrogen bonding between the phenylalkylamine secondary amine and the two glutamate residues. The predicted poses of the phenylalkylamines near the extracellular opening of the binding pocket are consistent with permissive SAR of these compounds. All complexes were further refined by local minimization in the presence of distance restraints maintaining receptor secondary and tertiary structures.

In contrast to phenylalkylamines, attempts to dock AC-265347 in the pocket placed E $767^{\mathrm{ECL} 2}$ and E837 $7^{7.38 / 32}$ in an unfavorable position, with the two acidic residues facing one another without a counter-ion to oppose their repulsion. Additionally, the highly restrictive SAR of compounds in the AC-265347 series [37] hints at a pocket that is closed from all sides. Based on these two considerations, the decision was made to dock AC-265347 further down in the TM binding pocket. As with the phenylalkylamines, docking 
was performed by extensive conformational sampling of the ligand and pocket residue side-chains; however, in contrast to the phenylalkylamines, this resulted in several plausible poses of the compound differing by its orientation inside the pocket and by rotamer states of phenylalanine residues. Thus, in an attempt to further refine our docking studies, we took advantage of the publication of two new $\mathrm{mGlu}_{5}$ crystal structures in complex with two novel compounds that bind in a similar location to our predicted AC-265347 binding site [55]. In fact, homologous residues to those where mutations alter AC-265347 $\mathrm{pK}_{\mathrm{B}}\left(\mathrm{W} 818^{6.50}, \mathrm{~F} 821^{6.53}\right.$ and $\left.\mathrm{A} 844^{7.39}\right)$ comprise the binding site of the novel $\mathrm{mGlu}_{5}$ allosteric ligands [55]. Homology modeling and docking were subsequently performed using all available structures of homologous proteins, including PDB: 4OR2 (GRM1), 4OO9, 5CGC and 5CGD (GRM5). Additional conformers were generated by backbone optimization of TM helices to better accommodate the non-conserved proline residues (e.g., P682 $2^{3.34}$ ), and by side-chain conformational sampling. These steps were undertaken with the goal of generating a conformationally variable ensemble from which each ligand would favorably recognize at least one of the conformations. Ultimately, for all three ligands, the best ranking models originated from the same PDB: 5CGD $\left(\mathrm{mGlu}_{5}\right)$. Phenylalkylamine ligand poses obtained in models built from other templates are generally consistent with those in the best model. The poses of AC-265347 have more variability although still appear consistent in the general location of the ligand-binding pocket.

\section{Acknowledgments}

This work was funded by Australian National Health and Medical Research Council (NHMRC; 1026962). AC is a Senior Principal Research Fellow, PMS is a Principal Research Fellow, and KJG is an Early Career Fellow of the NHMRC. IK and RA are supported by NIH (R01 GM071872, U01 GM094612, U54 GM094618, R01 AI118985, R21 AI121918 and R21 AI122211). We thank George Christopoulos for generation of the pcDNA3.1+ Gateway vector containing the influenza hemagglutinin signal peptide and c-myc tag.

\section{Author Contributions}

$\mathrm{KL}, \mathrm{ADC}$ and $\mathrm{AC}$ designed the study; KL, KJG, EK and AEC performed the experiments; KL and KJG performed the data analysis; IK and RA performed the molecular modeling and modulator docking studies; KL, KJG, IK, RA, ADC, PMS and AC contributed to writing the manuscript and preparing figures; $\mathrm{KL}$ and $\mathrm{AC}$ provided overall project supervision.

\section{Competing Financial Interests}

RA has an equity interest in Molsoft, LLC. The terms of this arrangement have been reviewed and approved by the University of California, San Diego, in accordance with its conflict of interest policies.

\section{References}

1 Brown EM. Role of the calcium-sensing receptor in extracellular calcium homeostasis. Best Pract Res Clin Endocrinol Metab 2013; 27:333-343.
2 Kantham L, Quinn SJ, Egbuna OI, et al. The calcium-sensing receptor (CaSR) defends against hypercalcemia independently of its regulation of parathyroid hormone secretion. $\mathrm{Am} \mathrm{J}$ Physiol Endocrinol Metab 2009; 297:E915-E923.

3 Loupy A, Ramakrishnan SK, Wootla B, et al. PTH-independent regulation of blood calcium concentration by the calcium-sensing receptor. J Clin Invest 2012; 122:3355-3367.

4 Freichel M, Zink-Lorenz A, Holloschi A, Hafner M, Flockerzi V, Raue F. Expression of a calcium-sensing receptor in a human medullary thyroid carcinoma cell line and its contribution to calcitonin secretion. Endocrinology 1996; 137:38423848 .

5 Marie PJ. The calcium-sensing receptor in bone cells: a potential therapeutic target in osteoporosis. Bone 2010; 46:571576.

6 Christopoulos A. Advances in GPCR allostery: from function to structure. Mol Pharmacol 2014; 86:463-478.

7 Aslan D, Andersen MD, Gede LB, et al. Mechanisms for the bone anabolic effect of parathyroid hormone treatment in humans. Scand J Clin Lab Invest 2012; 72:14-22.

8 Chonchol M, Locatelli F, Abboud HE, et al. A randomized, double-blind, placebo-controlled study to assess the efficacy and safety of cinacalcet $\mathrm{HCl}$ in participants with $\mathrm{CKD}$ not receiving dialysis. Am J Kidney Dis 2009; 53:197-207.

9 Fitzpatrick LA, Dabrowski CE, Cicconetti G, et al. Ronacaleret, a calcium-sensing receptor antagonist, increases trabecular but not cortical bone in postmenopausal women. $J$ Bone Miner Res 2012; 27:255-262.

10 Fitzpatrick LA, Smith PL, McBride TA, et al. Ronacaleret, a calcium-sensing receptor antagonist, has no significant effect on radial fracture healing time: results of a randomized, double-blinded, placebo-controlled Phase II clinical trial. Bone 2011; 49:845-852.

11 John MR, Harfst E, Loeffler J, et al. AXT914 a novel, orally-active parathyroid hormone-releasing drug in two early studies of healthy volunteers and postmenopausal women. Bone 2014; 64:204-210.

12 Widler L. Calcilytics: antagonists of the calcium-sensing receptor for the treatment of osteoporosis. Future Med Chem 2011; 3:535-547.

13 Kiefer L, Leiris S, Dodd RH. Novel calcium sensing receptor ligands: a patent survey. Expert Opin Ther Pat 2011; 21:681698.

14 Ma JN, Owens M, Gustafsson M, et al. Characterization of highly efficacious allosteric agonists of the human calcium-sensing receptor. J Pharmacol Exp Ther 2011; 337:275284.

15 Henley C 3rd, Yang Y, Davis J, et al. Discovery of a calcimimetic with differential effects on parathyroid hormone and calcitonin secretion. J Pharmacol Exp Ther 2011; 337:681691.

16 Leach K, Conigrave AD, Sexton PM, Christopoulos A. Towards tissue-specific pharmacology: insights from the calcium-sensing receptor as a paradigm for GPCR (patho)physiological bias. Trends Pharmacol Sci 2015; 36:215-225.

17 Leach K, Sexton PM, Christopoulos A. Allosteric GPCR modulators: taking advantage of permissive receptor pharmacology. Trends Pharmacol Sci 2007; 28:382-389.

18 Cook AE, Mistry SN, Gregory KJ, et al. Biased allosteric 
modulation at the CaSR engendered by structurally diverse calcimimetics. Br J Pharmacol 2015; 172:185-200.

19 Davey AE, Leach K, Valant C, Conigrave AD, Sexton PM, Christopoulos A. Positive and negative allosteric modulators promote biased signaling at the calcium-sensing receptor. Endocrinology 2012; 153:1232-1241.

20 Leach K, Wen A, Cook AE, Sexton PM, Conigrave AD, Christopoulos A. Impact of clinically relevant mutations on the pharmacoregulation and signaling bias of the calcium-sensing receptor by positive and negative allosteric modulators. Endocrinology 2013; 154:1105-1116.

21 Leach K, Sexton PM, Christopoulos A, Conigrave AD. Engendering biased signalling from the calcium-sensing receptor for the pharmacotherapy of diverse disorders. Br J Pharmacol 2014; 171:1142-1155.

22 Ray K, Northup J. Evidence for distinct cation and calcimimetic compound (NPS 568) recognition domains in the transmembrane regions of the human $\mathrm{Ca}^{2+}$ receptor. $J$ Biol Chem 2002; 277:18908-18913.

23 Ray K, Tisdale J, Dodd RH, Dauban P, Ruat M, Northup JK. Calindol, a positive allosteric modulator of the human $\mathrm{Ca}^{2+}$ receptor, activates an extracellular ligand-binding domain-deleted rhodopsin-like seven-transmembrane structure in the absence of $\mathrm{Ca}^{2+} . J$ Biol Chem 2005; 280:37013-37020.

24 Hauache OM, Hu J, Ray K, Xie R, Jacobson KA, Spiegel AM. Effects of a calcimimetic compound and naturally activating mutations on the human $\mathrm{Ca}^{2+}$ receptor and on $\mathrm{Ca}^{2+}$ receptor/metabotropic glutamate chimeric receptors. Endocrinology 2000; 141:4156-4163.

25 Mun HC, Franks AH, Culverston EL, Krapcho K, Nemeth EF, Conigrave AD. The Venus Fly Trap domain of the extracellular $\mathrm{Ca}^{2+}$-sensing receptor is required for L-amino acid sensing. J Biol Chem 2004; 279:51739-51744.

26 Petrel C, Kessler A, Maslah F, et al. Modeling and mutagenesis of the binding site of Calhex 231, a novel negative allosteric modulator of the extracellular $\mathrm{Ca}^{2+}$-sensing receptor. J Biol Chem 2003; 278:49487-49494.

27 Petrel C, Kessler A, Dauban P, Dodd RH, Rognan D, Ruat M. Positive and negative allosteric modulators of the $\mathrm{Ca}^{2+}$-sensing receptor interact within overlapping but not identical binding sites in the transmembrane domain. J Biol Chem 2004; 279:18990-18997.

$28 \mathrm{Bu}$ L, Michino M, Wolf RM, Brooks CL 3rd. Improved model building and assessment of the Calcium-sensing receptor transmembrane domain. Proteins 2008; 71:215-226.

29 Miedlich SU, Gama L, Seuwen K, Wolf RM, Breitwieser GE. Homology modeling of the transmembrane domain of the human calcium sensing receptor and localization of an allosteric binding site. J Biol Chem 2004; 279:7254-7263.

30 Dore AS, Okrasa K, Patel JC, et al. Structure of class C GPCR metabotropic glutamate receptor 5 transmembrane domain. Nature 2014; 511:557-562.

31 Wu H, Wang C, Gregory KJ, et al. Structure of a class C GPCR metabotropic glutamate receptor 1 bound to an allosteric modulator. Science 2014; 344:58-64.

32 Ballesteros JA, Weinstein H. Integrated methods for the construction of three-dimensional models and computational probing of structure-function relations in G protein-coupled receptors. In: Stuart CS, ed. Methods in Neurosciences. Aca- demic Press: San Diego, USA: 1995:366-428.

$33 \mathrm{Hu}$ J, Jiang J, Costanzi S, et al. A missense mutation in the seven-transmembrane domain of the human $\mathrm{Ca}^{2+}$ receptor converts a negative allosteric modulator into a positive allosteric modulator. J Biol Chem 2006; 281:21558-21565.

34 Leach K, Wen A, Davey AE, Sexton PM, Conigrave AD, Christopoulos A. Identification of molecular phenotypes and biased signaling induced by naturally occurring mutations of the human calcium-sensing receptor. Endocrinology 2012; 153:4304-4316.

35 Chen Y, Goudet C, Pin JP, Conn PJ. N-\{4-Chloro-2-[(1,3dioxo-1,3-dihydro-2H-isoindol-2-yl)methyl]phenyl $\}$-2-hydroxybenzamide (CPPHA) acts through a novel site as a positive allosteric modulator of group 1 metabotropic glutamate receptors. Mol Pharmacol 2008; 73:909-918.

36 Goudet C, Gaven F, Kniazeff J, et al. Heptahelical domain of metabotropic glutamate receptor 5 behaves like rhodopsin-like receptors. Proc Natl Acad Sci USA 2004; 101:378383.

37 Gustafsson M, Jensen J, Bertozzi SM, et al. Discovery of a class of calcium sensing receptor positive allosteric modulators; 1-(benzothiazol-2-yl)-1-phenylethanols. Bioorg Med Chem Lett 2010; 20:5918-5921.

38 Kruse AC, Ring AM, Manglik A, et al. Activation and allosteric modulation of a muscarinic acetylcholine receptor. Nature 2013; 504:101-106.

39 Jaakola VP, Griffith MT, Hanson MA, et al. The 2.6 angstrom crystal structure of a human A2A adenosine receptor bound to an antagonist. Science 2008; 322:1211-1217.

40 Wang C, Wu H, Evron T, et al. Structural basis for Smoothened receptor modulation and chemoresistance to anticancer drugs. Nat Commun 2014; 5:4355.

41 Weierstall U, James D, Wang C, et al. Lipidic cubic phase injector facilitates membrane protein serial femtosecond crystallography. Nat Commun 2014; 5:3309.

42 Tsuchiya D, Kunishima N, Kamiya N, Jingami H, Morikawa K. Structural views of the ligand-binding cores of a metabotropic glutamate receptor complexed with an antagonist and both glutamate and Gd3+. Proc Natl Acad Sci USA 2002; 99:2660-2665.

43 Kunishima N, Shimada Y, Tsuji Y, et al. Structural basis of glutamate recognition by a dimeric metabotropic glutamate receptor. Nature 2000; 407:971-977.

44 Muto T, Tsuchiya D, Morikawa K, Jingami H. Structures of the extracellular regions of the group II/III metabotropic glutamate receptors. Proc Natl Acad Sci USA 2007; 104:37593764.

45 Monn JA, Prieto L, Taboada L, et al. Synthesis and pharmacological characterization of C4-disubstituted analogs of 1S,2S,5R,6S-2-aminobicyclo[3.1.0]hexane-2,6-dicarboxylate: identification of a potent, selective metabotropic glutamate receptor agonist and determination of agonist-bound human mGlu2 and mGlu3 amino terminal domain structures. $J$ Med Chem 2015; 58:1776-1794.

46 Rovira X, Malhaire F, Scholler P, et al. Overlapping binding sites drive allosteric agonism and positive cooperativity in type 4 metabotropic glutamate receptors. FASEB J 2015; 29:116-130.

47 Ward BK, Magno AL, Walsh JP, Ratajczak T. The role of the 
calcium-sensing receptor in human disease. Clin Biochem 2012; 45:943-953.

48 Yarova PL, Stewart AL, Sathish V, et al. Calcium-sensing receptor antagonists abrogate airway hyperresponsiveness and inflammation in allergic asthma. Sci Transl Med 2015; 7:284ra260

49 Nemeth EF, Delmar EG, Heaton WL, et al. Calcilytic compounds: potent and selective $\mathrm{Ca}^{2+}$ receptor antagonists that stimulate secretion of parathyroid hormone. J Pharmacol Exp Ther 2001; 299:323-331.

50 Gowen M, Stroup GB, Dodds RA, et al. Antagonizing the parathyroid calcium receptor stimulates parathyroid hormone secretion and bone formation in osteopenic rats. J Clin Invest 2000; 105:1595-1604.

51 Christopoulos A. Assessing the distribution of parameters in models of ligand-receptor interaction: to $\log$ or not to $\log$. Trends Pharmacol Sci 1998; 19:351-357.

52 Abagyan R, Totrov M. Biased probability Monte Carlo conformational searches and electrostatic calculations for pep- tides and proteins. J Mol Biol 1994; 235:983-1002.

53 Lee B, Richards FM. The interpretation of protein structures: estimation of static accessibility. J Mol Biol 1971; 55:379400.

54 Stiefl N, Gedeck P, Chin D, et al. FOCUS - Development of a global communication and modeling platform for applied and computational medicinal chemists. J Chem Inf Model 2015; 55:896-908.

55 Christopher JA, Aves SJ, Bennett KA, et al. Fragment and structure-based drug discovery for a Class C GPCR: discovery of the mGlu5 negative allosteric modulator HTL14242 (3-Chloro-5-[6-(5-fluoropyridin-2-yl)pyrimidin-4-yl]benzonitrile). J Med Chem 2015; 58:6653-6664.

56 Venkatakrishnan AJ, Deupi X, Lebon G, Tate CG, Schertler GF, Babu MM. Molecular signatures of G-protein-coupled receptors. Nature 2013; 494:185-194.

57 Bortolato A, Dore AS, Hollenstein K, Tehan BG, Mason JS, Marshall FH. Structure of Class B GPCRs: new horizons for drug discovery. Br J Pharmacol 2014; 171:3132-3145.

(Supplementary information is linked to the online version of the paper on the Cell Research website.) 